\title{
Transactive Control and Coordination of Distributed Assets for Ancillary Services
}

Kris Subbarao

Jason Fuller

Karanjit Kalsi

Rob Pratt

Steve Widergren

David Chassin

September 2013

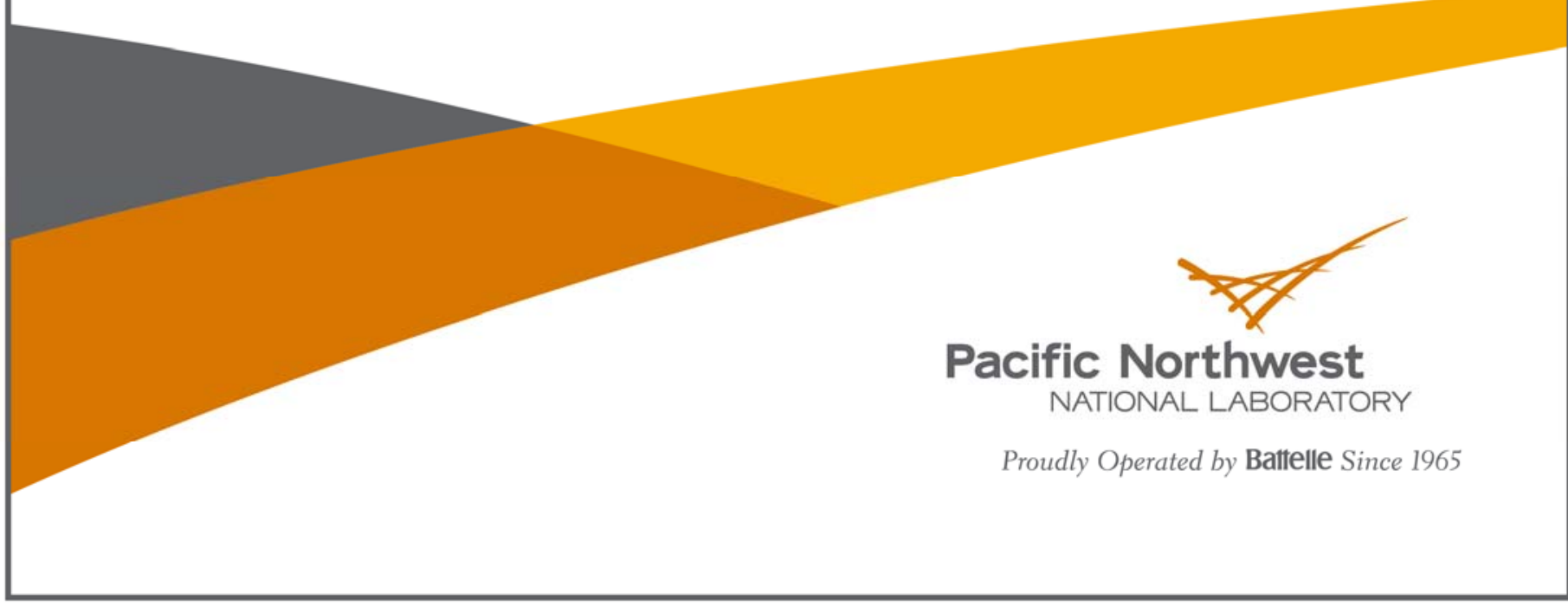




\title{
DISCLAIMER
}

This report was prepared as an account of work sponsored by an agency of the United States Government. Neither the United States Government nor any agency thereof, nor Battelle Memorial Institute, nor any of their employees, makes any warranty, express or implied, or assumes any legal liability or responsibility for the accuracy, completeness, or usefulness of any information, apparatus, product, or process disclosed, or represents that its use would not infringe privately owned rights. Reference herein to any specific commercial product, process, or service by trade name, trademark, manufacturer, or otherwise does not necessarily constitute or imply its endorsement, recommendation, or favoring by the United States Government or any agency thereof, or Battelle Memorial Institute. The views and opinions of authors expressed herein do not necessarily state or reflect those of the United States Government or any agency thereof.

\author{
PACIFIC NORTHWEST NATIONAL LABORATORY \\ operated by \\ BATTELLE \\ for the \\ UNITED STATES DEPARTMENT OF ENERGY \\ under Contract DE-AC05-76RL01830
}

Printed in the United States of America
Available to DOE and DOE contractors from the Office of Scientific and Technical Information,
P.O. Box 62, Oak Ridge, TN 37831-0062;
ph: (865) 576-8401
fax: $(865)$ 576-5728
email: reports@adonis.osti.gov

\begin{abstract}
Available to the public from the National Technical Information Service, U.S. Department of Commerce, 5285 Port Royal Rd., Springfield, VA 22161 ph: (800) 553-6847 fax: $(703) 605-6900$ email: orders@ntis.fedworld.gov online ordering: http://www.ntis.gov/ordering.htm
\end{abstract}

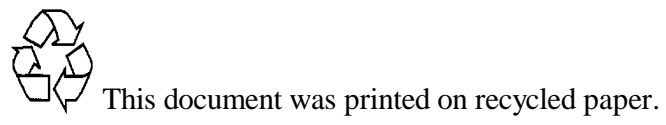




\section{Transactive Control and Coordination of Distributed Assets for Ancillary Services}

September 2013

Prepared for

the U.S. Department of Energy

under Contract DE-AC05-76RL01830

Pacific Northwest National Laboratory

Richland, Washington 99352 


\section{Executive Summary}

The need to diversify energy supplies, the need to mitigate energy-related environmental impact, and the entry of electric vehicles in large numbers present challenges and opportunities to power system professionals. Wind and solar power provide many benefits, and to reap the benefits the resulting increased variability - forecasted as well as unforecasted — should be addressed. A majority of states and the District of Columbia, representing over half of the total load, have passed renewable portfolio standards. California's plans call for 33\% renewable energy by 2020 . For grid balancing and for meeting reliability standards, ancillary services are needed. The needs for these services are poised to increase significantly. Demand resources are receiving increasing attention as one means of providing the ancillary services.

Distributed demand resources have a recognized role in reducing peak loads and in economical load response when wholesale energy prices are high. Distributed demand response assets may also provide ancillary services at a cost and quality competitive with generators, which provide a very large part of ancillary services. In some areas, demand resources can participate in providing some ancillary services - spinning and non-spinning reserves; this is largely restricted to large commercial and industrial loads. Participation by a large number ( $\sim$ millions $)$ of distributed assets can potentially lower cost and increase the reliability of the grid. A number of questions need to be answered for such participation: Will the devices provide the expected quantity of service at the expected time? Will the collective performance lead to potential undesirable behavior? How should the current market structures -typically day ahead schedules, updates as needed, short-term commitment of devices, and real-time dispatch, as well as largely decoupled wholesale and retail markets be modified to facilitate large scale participation by distributed devices? These questions are the subject of intense study by various researchers. In this report, the scope is limited to solutions of some important technical issues and an approach to real-time dispatch for ancillary services is proposed.

Control and coordination of a large number ( $\sim$ millions) of distributed smart grid assets requires innovative approaches. One such approach is transactive control and coordination (TC2) - a distributed, hierarchical, agent-based incentive and control system. The TC2 paradigm is to create a market-like control system in which participation is voluntary and the participant sets the price for participation. For transactions that are frequent, automation of bids and responses is necessary.

Such an approach has been developed and demonstrated at the Pacific Northwest National Laboratory. The devices, typically thermostatically controlled heating, ventilating, and air conditioning (HVAC) loads, send their bids - the quantity of energy they need and, based on the consumer preferences encoded in a simple user interface, the price they are willing to pay. The typical bid period is 5 minutes. By aggregating all the bids, a demand curve is generated by the aggregating entity, and matched with a supply curve or supply constraint. The aggregator transmits the clearing price to the devices. The winning devices proceed to consume the energy they bid for and won. It is the purpose of this project to develop a similar approach for ancillary services.

In this report, the following ancillary services are considered: spinning reserve, ramping, and regulation. These services are to be provided by the following devices: refrigerators, water heaters, clothes dryers, variable speed drives. We will assume that the variable speed drives operate an air handling fan in a commercial building. 
The analysis considers the following issues that arise in developing TC2: availability of devices, market structure, communication with devices, control of devices, measurement and verification of services provided. This report provides the analysis necessary to develop specifications for simulations of a TC2 system with a range of characteristics of the devices, characteristics of the service they are required to provide, market designs, control strategies. Some of the results are of interest in the broader context of ancillary services regardless of the implementation mechanism.

The specifications, execution, and analysis of the simulations and formulation of desirable market designs and control strategies are recommended for the future. In the longer term, the capabilities of the devices, as well as of communication and control, are expected to grow. Some ancillary services, (for example, absorbing higher-than-forecast renewable generation), require demand resources to respond by increasing their energy use; enabling technology is likely to emerge in the future. Furthermore, new market designs can facilitate participation by a large number of devices. In the near term, the foundational capabilities of TC2 will be examined with realistic simulations and markets, as well as laboratory-scale tests and demonstration projects.

The important results are summarized below:

- The regulation signal can be divided into an energy-neutral high frequency component and a low frequency component. The high frequency component is particularly well suited for demand resources. The low frequency component, which carries energy non-neutrality, can be handled by a combination of generators and demand resources. An explicit method for such a separation is obtained from an exponentially weighted moving average filter. Causal filters (i.e., filters that process only present and past values of a signal) introduce delays that can be issues in some signal processing applications that treat the high frequency part as a noise to be eliminated. For regulation, the high frequency component is an essential part of the signal. The delay in the low frequency component is not a problem.

A transactive bidding mechanism determines the set of devices chosen to provide the regulation service. The devices have to respond every few seconds (e.g., every 4 seconds) to the regulation signal. To keep the communication and computational burden manageable, the bidding interval is typically much longer (e.g., 5 minutes). A stochastic self-dispatch algorithm determines the response of the devices to the regulation signal.

The energy neutrality interval varies and can be quite different from the bid interval (e.g., 30 minutes versus 5 minutes). Devices that have just provided regulation up by reducing their energy use are in a better position to provide regulation down. Future simulation studies of the transactive mechanism for regulation are proposed.

- In an ensemble of devices under normal operation, some devices turn on and some turn off in any time interval. Demand response necessitates turning off devices that would normally be on, or turning on devices that would normally be off. Over time, some of these would have turned off on their own. A formalism to determine expectation values under a combination of natural and forced attrition has been developed. This formalism provides a mechanism for accomplishing a desired power profile within a bid period. In particular, a method to minimize regulation requirement can be developed. The formulation provides valuable insights into control. More realistic scenarios including multiple states of the devices can be analyzed using simulations. As historical data on the performance of devices become available, control algorithms can be refined. Methods developed for primary frequency control using a large number of heterogeneous devices may be relevant. 
A transactive bidding mechanism gives the set of devices chosen to provide the service. Analyses of the bidding and dispatch mechanisms for such a service through simulations are needed.

- If a contingency spans multiple bidding intervals, there is the possibility of gaming the system by bidding high in subsequent intervals. Analyses of methods for defending against such possibilities are needed.

- Some ancillary services - ramping to absorb unforecasted increase in renewable generation, and regulation down - require the demand resources to increase their energy use. Some resources such as HVAC systems can do this readily, whereas some others require enabling technology. Even without such technology, it is possible to arrange refrigerators and water heaters to have an energy debt and be ready to increase their energy use. A transactive bid mechanism of revolving debt can be developed for this purpose. Analyses of the bidding and dispatch mechanisms for such revolving energy debt through simulations are needed.

- At the end of a contingency call, the devices should be returned to their pre-contingency condition. This should be staged in a way that avoids a rebound in load resulting from too many devices turning on at once. A stochastic mechanism is one approach. Another is for the aggregator to plan for it in the energy market. A third is, in effect, a one-sided auction where the devices compete for an amount of energy that avoids such peaks. Analysis of measurement and verification of services using interval meter data, possibly augmented by non-intrusive load monitoring techniques are needed.

Identification of mechanisms available or likely to be available in the near future for communicating with a large number of devices, especially broadcasting regulation signals in a form appropriate for devices to respond are needed. These include internet and radio communications.

As noted earlier, dramatic changes in control systems, architecture and markets are expected in the electrical grid. The technical capabilities of a large number of devices interacting with the grid are changing. While it is too early to describe complete solutions, TC2 has attractive features suitable for adapting to the changes. The analysis in this report identifies the activities needed to facilitate this transition. 



\section{Acknowledgments}

Some of the research described in this report was conducted by D.C. in collaboration with Dr. Ned Djilali at the University of Victoria in Victoria BC, Canada. We acknowledge the participation of Jianming Lian in discussions. 



\section{Acronyms and Abbreviations}

ACE

AEP

CAISO

DOE

DR

ELCAP

ERCOT

EWMA

FERC

HVAC

ISO

LMP

LSE

$\mathrm{M} \& \mathrm{~V}$

MISO

NERC

NILM

NYISO

PJM

PNNL

PNWSG

RTO

SCED

SCUC

TC2

TESA

VSD

area control error

American Electric Power

California Independent System Operator

U.S. Department of Energy

Demand Response

End Use Load and Consumer Assessment Program

Electric Reliability Council of Texas, Inc.

exponentially weighted moving average

Federal Energy Regulatory Commission

heating, ventilation, and air conditioning

independent system operator

locational marginal price

load serving entity

measurement and verification

Midcontinent Independent System Operator, Inc.

North American Electric Reliability Corporation

nonintrusive load monitoring

New York Independent System Operator

a regional transmission organization in some eastern states and the District of Columbia

Pacific Northwest National Laboratory

Pacific Northwest Smart Grid Demonstration Project

regional transmission organization

security constrained economic dispatch

security constrained unit commitment

transactive control and coordination

Texas Energy Storage Alliance

variable speed drive 



\section{Contents}

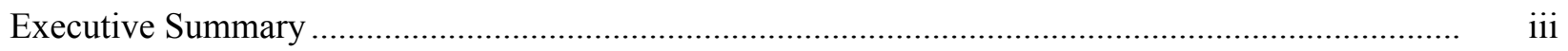

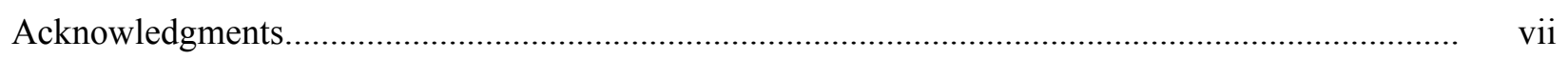

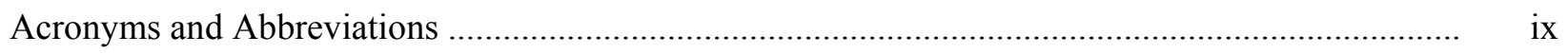

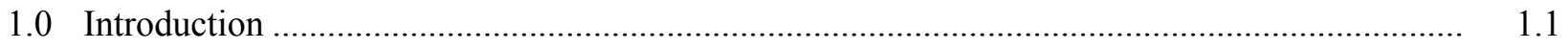

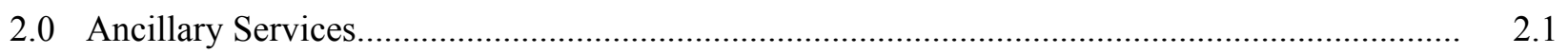

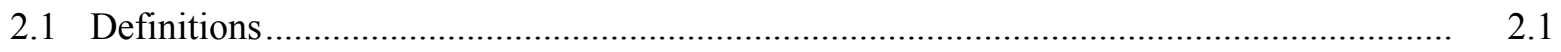

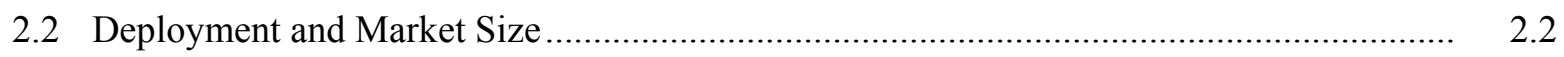

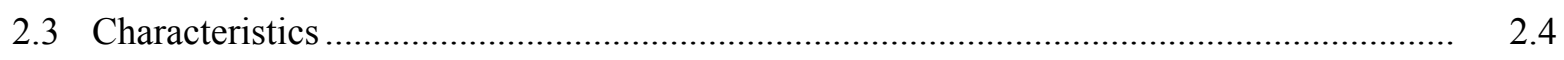

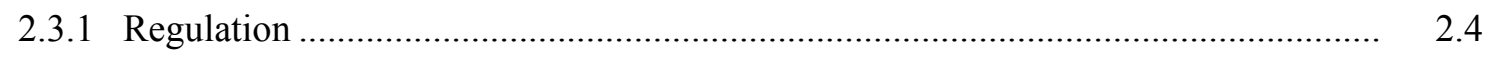

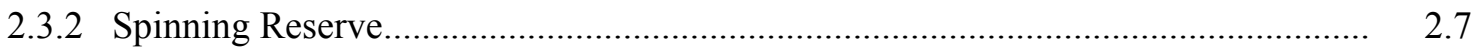

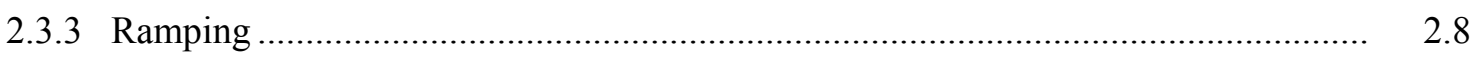

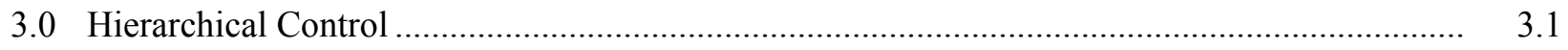

3.1 Market-Based Services......................................................................................

3.2 Device-Level Controls ........................................................................................ 3.3

4.0 Demand Resources for Ancillary Services - Barriers .....................................................

5.0 Availability and Load Shapes ....................................................................................... 5.1

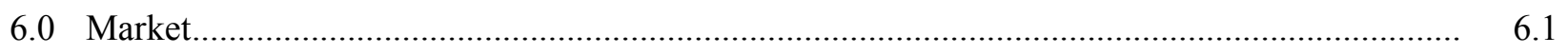

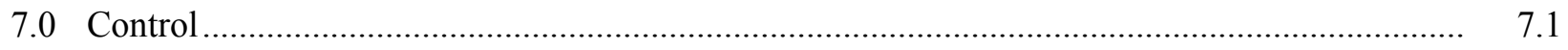

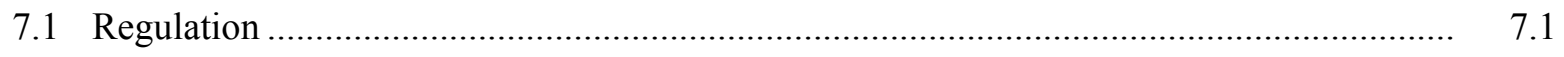

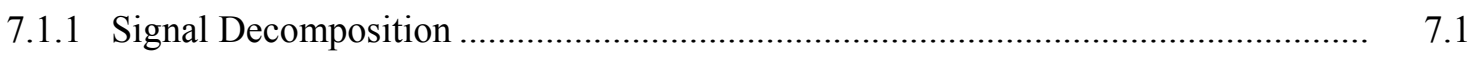

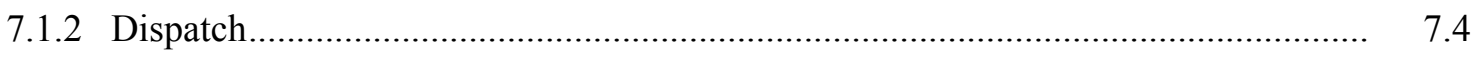

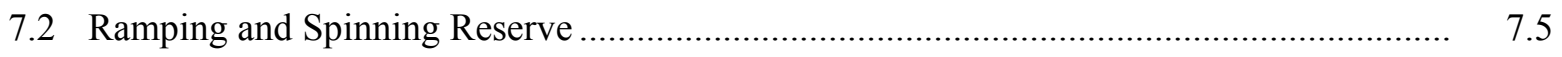

8.0 Communication, Measurement, and Verification........................................................... 8.1

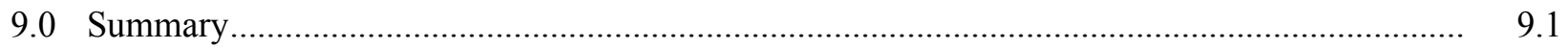

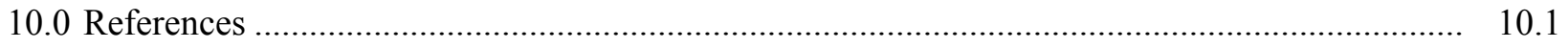

\section{Figures}

2.1 Regulation-A Requirement in 2-sec Intervals for January 9, 2013 ..................................... 2.5

2.2 Regulation-D Requirement in 2-sec Intervals for January 9, 2013 ...................................... 2.6

2.3 ACE Signal and Total Regulation Deployed by ERCOT on October 27, 2010 ....................... 2.7

2.4 The PJM Electricity Market in September 2006: Spinning Reserve Capacity Requirement

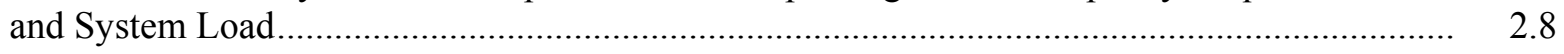

3.1 Hierarchical Control of Electric Interconnections .............................................................. 3.2

3.2 Device Control with Price-Based Bid Feedback.................................................................. 3.4 
5.1 Typical Load Shapes for a Water Heater Extracted from ELCAP Data .................................... 5.3

5.2 Typical Load Shapes for a Refrigerator Extracted from ELCAP Data..................................... 5.3

5.3 Typical Load Shapes for a Clothes Dryer Extracted from ELCAP Data.................................. 5.3

5.4 Typical Load Shapes for Heating and Cooling Extracted from ELCAP Data............................ 5.4

5.5 Typical Daily Cooling Load as a Function of Time for a Medium Size Office Building in a Hot and Humid Climate .............................................................................................. 5.4

5.6 Power Draw from a VSD Supply Fan in a Commercial Building on a Typical Weekday .......... 5.5

5.7 Profile of the Fan Speed of an Air Handler with VSD over a 24-hour Period ........................... 5.5

7.1 A Plot of PJM Regulation-D Signal and the Cumulative Value .............................................. 7.2

7.2 Low Pass Signal and its Cumulative Value ..........................................................................

7.3 Regulation Signal with the Low Pass Component Subtracted..................................................

7.4 A Plot of the Signals Restricted to the Interval Between 6 p.m. and 6:30 p.m......................... 7.3

7.5 A Schematic Illustration of Paths an Ensemble of Devices can take during 5 minutes................ $\quad 7.6$

\section{Tables}

2.1 Characteristics of Different Ancillary Services ............................................................. 2.2

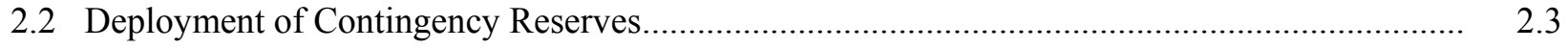

2.3 Procurement in 2011 of Some Ancillary Services as a Percentage of Average Load ................. 2.3

2.4 Average Hourly In-Market Capacity Procurement Volume ...................................................... 2.3

2.5 Annual Average Market Clearing Prices for Regulation and Spinning Reserves in U.S. ISO/RTOs

5.1 Approximate Demand of Individual Processes within a Residential Refrigerator .................... 5.5 


\subsection{Introduction}

The need to diversify energy supplies, the need to mitigate energy-related environmental impact, and the entry of electric vehicles in large numbers present challenges and opportunities to power system professionals. To reap the many benefits of wind and solar power the resulting increased variabilityforecasted as well as unforecasted - should be addressed. A majority of states and the District of Columbia, representing over half of the total load, have passed renewable portfolio standards (EIA 2012). California's plans call for 33\% renewable energy by 2020. For grid balancing and for meeting reliability standards, ancillary services are needed for the following functions:

- Maintain frequency within standard ranges, and maintain net import/export of power in a balancing authority according its market or production dispatch schedule (regulation).

- Provide adequate reserve capacity to withstand contingencies involving the loss of any asset in the system (spinning reserve).

- Manage intermittent and unpredicted changes in output from renewable generation (ramping).

The needs for these services are poised to increase significantly. Demand resources are receiving increasing attention as one means of providing the ancillary services. The literature on this topic is quite large and growing. Good discussions can be found in DOE (2011), Pratt and Najewicz (2011), MacDonald et al. (2012), Perlstein et al. (2012), and Cappers et al. (2013) as well as in references therein.

Current practice in power systems is to provide ancillary services by using power plant capacity. This results in tying up expensive capital investment, operating the generators at potentially lower efficiency, and increasing wear and tear from continually adjusting their output in response to the immediate balancing needs of the grid. Distributed demand response assets can provide equivalent services potentially at a lower cost by adjusting load rather than power plant output. They can provide faster response than power plants and can effectively reduce the need for regulation and lower the cost of regulation. Even the general media has taken notice of the role of demand resources in grid balancing (Shogren 2013).

Since most ancillary services are short in duration, the impact on customer services of tapping demand resources can be minimal or even negligible. Given the chance to earn incentives from the grid, and because there is very low capital investment to recover, such assets can offer ancillary services at very low cost, and form a vast new reliability resource for the grid. In De Martini (2013), De Martini identifies "thirty different value streams ... that conceivably may increasingly be met by [demand] resources over this decade." The ancillary services considered in this report are some of these value streams. Although the market size may be growing, the value available per device is not likely to grow at the same rate. The cost-effectiveness of adding features to the devices must be carefully evaluated.

Control and coordination of a very large number ( $\sim$ millions $)$ of distributed smart grid assets requires innovative approaches. One such is transactive control and coordination (TC2), a distributed, agent-based incentive and control system. TC2 is envisioned as an element of hierarchical control of the electrical grid. An explanation of this hierarchy and of TC2 as implemented in several demonstration projects by 
Pacific Northwest National Laboratory (PNNL) is given in Section 1. Here we will note that the TC2 paradigm is to create a market system with the following characteristics: a) Participation should be entirely voluntary, b) The participant decides at what price he is willing to participate, and (c) for large scale participation in service requiring fast response, the bids and responses are automated.

With these principles in mind, TC2 demonstration projects developed a slider that the homeowner can adjust that translates to a price at which s/he will participate. The automated bid price reflects the slider setting. A similar arrangement is envisioned for TC2 ancillary services. In its prototypical implementation, each participating device generates a bid - a quantity and a price - for every bid period (e.g., 5 minutes) and communicates it to the aggregating entity. The bids are generated by suppliers as well as consumers. The market clearing price is broadcast and the devices with cleared bids perform. Many refinements of this simple mechanism are necessary for a field-deployable system, and these are described in this report.

In this report, the following ancillary services are considered: (a) spinning reserve, (b) ramping and (c) regulation. These services are to be provided by the following devices: (a) refrigerators, (b) water heaters, (c) clothes dryers, and (d) variable speed drives (VSDs). We will assume that the VSD is the motor of an air handling fan in a commercial building.

The analysis considers the following issues that arise in developing TC2: (a) availability of devices (b) market structure (c) communication with devices (d) control of devices and (e) measurement and verification $(\mathrm{M} \& \mathrm{~V})$ of services provided. This report provides the analysis necessary to develop specifications for simulations of a TC2 system with a range of (a) characteristics of the devices (b) characteristics of the service they are required to provide (c) market designs and (c) control strategies.

The specifications, execution and analysis of the simulations and formulation of desirable market designs and control strategies are planned future activities. In the longer term, the capabilities of the devices, as well as of communication and control, are expected to grow. Some ancillary services, (for example, absorbing higher-than-forecast renewable generation), require demand resources to respond by increasing their energy use; enabling technology is likely to emerge in the future. Furthermore, new market designs can facilitate participation by a large number of devices. In the near term, the foundational capabilities of TC2 will be examined with realistic simulations and markets, as well as laboratory-scale tests and demonstration projects. Some technology and market assumptions are made in this near-term context. 


\subsection{Ancillary Services}

\subsection{Definitions}

It is important to establish some common terminology. The Federal Energy Regulatory Commission (FERC) defines the following ancillary services in the July 2012 document, Energy Primer: A Handbook of Energy Market Basics (FERC 2012):

"Ancillary services maintain electric reliability and support the transmission of electricity. These services are produced and consumed in real-time, or in the very near term. NERC and regional entities establish the minimum amount of each ancillary service that is required for maintaining grid reliability.

Regulation matches generation with very short-term changes in load by moving the output of selected resources up and down via an automatic control signal, typically every few seconds. The changes are designed to maintain system frequency at 60 hertz. ${ }^{1}$ Failure to maintain a 60-hertz frequency can result in collapse of an electric grid.

Operating reserves are needed to restore load and generation balance when a generating unit trips off line. Operating reserves are provided by generating units and demand resources that can act quickly, by increasing output or reducing demand, to make up a generation deficiency. There are three types:

1. Spinning reserves are primary. To provide spinning reserve a generator must be on line (synchronized to the system frequency) with some unloaded (spare) capacity and be capable of increasing its electricity output within 10 minutes. During normal operation these reserves are provided by increasing output on electrically synchronized equipment or by reducing load on pumped storage hydroelectric facilities. Synchronized reserve can also be provided by demand-side resources.

2. Nonspinning reserves come from generating units that can be brought online in 10 minutes. Nonspinning reserve can also be provided by demand-side resources.

3. Supplemental reserves come from generating units that can be made available in 30 minutes and are not necessarily synchronized with the system frequency. Supplemental reserves are usually scheduled in the day-ahead market, allowing generators to offer their reserve energy at a price, thus compensating cleared supply at a single market clearing price. This only applies to ISO/RTOs, and not all reliability regions have a supplemental reserve requirement."

In common usage, regulation and operating reserves are referred to as ancillary services. Another service discussed as an ancillary service, although not defined by FERC as such, is flexibility ramping service. With increased penetration of wind and solar, the need for addressing ramps caused by forecasted or unforecasted energy imbalance is emerging as a service in its own right. Without this service, grid balancing can result in expensive resources being deployed. We will refer to this ancillary

\footnotetext{
${ }^{1}$ Regulation also needs to account for the differences between scheduled and actual interchange at interconnections with other balancing authorities. An excellent review can be found in NERC (2011).
} 
service as ramping. The market for this service is in its early stages. For example, assessments of California's evolving electricity market are given in Casey (2013) and CAISO (2011).

Although the details may vary, Table 2.1, adapted from EPRI (2003), gives a general description of ancillary services with some notes that go beyond FERC descriptions.

Table 2.1. Characteristics of Different Ancillary Services (adapted from EPRI (2003))

\begin{tabular}{|c|c|c|}
\hline Service & Service Description & $\begin{array}{l}\text { Typical Response Times and } \\
\text { Performance Periods }\end{array}$ \\
\hline Regulation & $\begin{array}{l}\text { Power sources online, on automatic generation } \\
\text { control, that can respond rapidly to system-operator } \\
\text { requests for up and down movements; used to track } \\
\text { the minute-to-minute fluctuations in system load and } \\
\text { to correct for unintended fluctuations in generator } \\
\text { output to comply with the North American Electric } \\
\text { Reliability Corporation's (NERC's) Control } \\
\text { Performance Standards (CPS) } 1 \text { and } 2\end{array}$ & $\begin{array}{l}\text { System response within about } \\
1 \text { minute to continuously correct } \\
\text { cyclic variations in grid frequency } \\
\text { ranging from } 2 \text { to } 20 \text { cycles per } \\
\text { hour. Continuous within the bid } \\
\text { period. }\end{array}$ \\
\hline $\begin{array}{l}\text { Spinning } \\
\text { Reserve }\end{array}$ & $\begin{array}{l}\text { Power sources online, synchronized to the grid, that } \\
\text { can increase output immediately in response to a } \\
\text { major generator or transmission outage and can reach } \\
\text { full output within } 10 \text { minutes to comply with NERC's } \\
\text { Disturbance Control Standard (DCS) }\end{array}$ & $\begin{array}{l}\text { Immediate response reaching full } \\
\text { power within about } 10 \text { minutes and } \\
\text { providing full power for up to } \\
1 \text { hour, called upon } 5 \text { to } 20 \text { times per } \\
\text { year }\end{array}$ \\
\hline $\begin{array}{l}\text { Non-Spinning } \\
\text { Reserve }\end{array}$ & $\begin{array}{l}\text { Same as spinning reserve, but need not respond } \\
\text { immediately; therefore, units can be offline but still } \\
\text { must be capable of reaching full output within the } \\
\text { required } 10 \text { minutes }\end{array}$ & $\begin{array}{l}\text { Full power within about } 10 \text { minutes } \\
\text { to provide power for up to } 2 \text { hours, } \\
\text { called upon } 5 \text { to } 20 \text { times per year }\end{array}$ \\
\hline Flexibility/Ramping & $\begin{array}{l}\text { Additional load following reserve for large } \\
\text { unforecasted wind/solar ramps }\end{array}$ & $\begin{array}{l}\text { System response within about } \\
5 \text { minutes reaching full response } \\
\text { within } 20 \text { minutes; length of } \\
\text { response about } 1 \text { hour. Continuous } \\
\text { within the bid period. }\end{array}$ \\
\hline $\begin{array}{l}\text { Replacement } \\
\text { Reserve }\end{array}$ & $\begin{array}{l}\text { Same as non-spinning reserve, but with a } 30 \text {-minute } \\
\text { response time, used to restore spinning and } \\
\text { supplemental reserves to their pre-contingency status }\end{array}$ & $\begin{array}{l}\text { Full power within about } 30 \text { minutes } \\
\text { to provide power for up to } 2 \text { hours, } \\
\text { called upon } 5 \text { to } 20 \text { times per year }\end{array}$ \\
\hline
\end{tabular}

Spinning, non-spinning, and supplemental reserves are often collectively referred to as contingency reserves. In this report, we focus on spinning reserves, ramping, and regulation. Non-spinning reserve and replacement reserve share the characteristics of spinning reserve except for the response time and period of performance. TC2 formulation for these is similar to that for spinning reserve and is not considered explicitly.

\subsection{Deployment and Market Size}

Regulation is a service that is needed at all times. In response to the area control error (ACE) (NERC 2011), which is a measure of the deviation of the grid frequency from the reference frequency and of the deviation from schedule of energy interchange with other balancing areas, the system should change generation or load by an amount equal to the ACE. The ramping service is required quite frequently, but 
an explicit market is still in its early stages. Spinning reserve is deployed quite infrequently. The deployment durations of all contingencies are shown in Table 2.2.

Table 2.2. Deployment of Contingency Reserves (adapted from Kirby (2006))

\begin{tabular}{lccc}
\hline \multicolumn{1}{c}{ ISO } & Year & Number of Times Deployed & Average Duration \\
\hline NYISO & 2002 & 239 & $<11 \mathrm{~min}$ \\
ISO-NE & 2005 & 19 & $<11 \mathrm{~min}$ \\
CAISO & 2005 & 26 & $<9$ min \\
\hline
\end{tabular}

Procurement of ancillary service can be cost based or market based: Cost-based services are offered at predetermined regulated costs, and market-based services are provided at market rates. Some entities may provide their own ancillary services without a transaction with another party.

The trend is for the procurement to occur in smaller increments from multiple participants. For example, the minimum bid size in the California Independent System Operator (CAISO) demand response market is $100 \mathrm{~kW}$ (EPRI 2003). The size of the procurement and average prices are briefly discussed below (Table 2.3, Table 2.4, and Table 2.5).

Table 2.3. Procurement in 2011 of Some Ancillary Services as a Percentage of Average Load (as reported in MacDonald et al. 2012)

\begin{tabular}{lcc}
\hline & Regulation & Spinning Reserve \\
\hline CAISO & $0.7 \%$ & $2 \%$ \\
ERCOT & $1.6 \%$ & $4.5 \%$ \\
MISO & $0.6 \%$ & $1.5 \%$ \\
PJM & $1 \%$ & \\
\hline
\end{tabular}

Table 2.4. Average Hourly In-Market Capacity Procurement Volume

Average hourly in-market capacity procurement volume for some U.S. Independent System Operators/Regional Transmission Organizations from 2009-2011 (Darker cell shades indicate real-time markets, lighter are day-ahead markets)

\begin{tabular}{|c|c|c|c|c|}
\hline & \multicolumn{3}{|c|}{$\begin{array}{l}\text { Regulation } \\
\text { (MWh) }\end{array}$} & \multirow[t]{2}{*}{$\begin{array}{c}\text { Spinning Reserves } \\
\text { (MWh) }\end{array}$} \\
\hline & $\mathrm{Up}$ & Down & Combined & \\
\hline CAISO-South & 91 & 94 & & 227 \\
\hline CAISO-North & 92 & 98 & & 289 \\
\hline ERCOT & 628 & 606 & & 1715 \\
\hline MISO & & & 396 & 978 \\
\hline PJM & & & 824 & 418 \\
\hline
\end{tabular}


Table 2.5. Annual Average Market Clearing Prices $(\$ / M W h)$ for Regulation and Spinning Reserves in U.S. ISOs/RTOs (as reported in MacDonald et al. 2012)

\begin{tabular}{|c|c|c|c|c|c|c|c|c|c|}
\hline \multirow[t]{3}{*}{$\begin{array}{l}\text { ISO (Reserve } \\
\text { Zone) }\end{array}$} & \multicolumn{6}{|c|}{ Regulation } & \multicolumn{3}{|c|}{$\begin{array}{c}\text { 10-min Spinning } \\
\text { Reserves }\end{array}$} \\
\hline & \multicolumn{2}{|c|}{2009} & \multicolumn{2}{|c|}{2010} & \multicolumn{2}{|c|}{2011} & \multirow[b]{2}{*}{2009} & \multirow[b]{2}{*}{2010} & \multirow[b]{2}{*}{2011} \\
\hline & $\mathrm{Up}$ & Down & $\mathrm{Up}$ & Down & $\mathrm{Up}$ & Down & & & \\
\hline CAISO (South) & NA & & $\$ 8.06$ & $\$ 6.75$ & $\$ 11.93$ & $\$ 7.27$ & NA & $\$ 5.24$ & $\$ 9.45$ \\
\hline CAISO (North) & NA & & $\$ 5.64$ & $\$ 4.98$ & $\$ 9.21$ & $\$ 6.93$ & NA & $\$ 4.07$ & $\$ 7.23$ \\
\hline ERCOT & $\$ 9.70$ & $\$ 7.25$ & $\$ 9.81$ & $\$ 8.27$ & $\$ 22.67$ & $\$ 8.58$ & $\$ 9.95$ & $\$ 9.09$ & $\$ 22.92$ \\
\hline MISO & \multicolumn{2}{|c|}{$\$ 12.43$} & \multicolumn{2}{|c|}{$\$ 12.17$} & \multicolumn{2}{|c|}{$\$ 10.83$} & $\$ 4.03$ & $\$ 4.02$ & $\$ 4.03$ \\
\hline $\mathrm{PJM}^{(\mathrm{a})}$ & \multicolumn{2}{|c|}{$\$ 23.51$} & \multicolumn{2}{|c|}{$\$ 17.95$} & \multicolumn{2}{|c|}{$\$ 16.42$} & $\$ 4.83$ & $\$ 5.72$ & $\$ 7.91$ \\
\hline NYISO (East) & \multicolumn{2}{|c|}{$\$ 37.20$} & \multicolumn{2}{|c|}{$\$ 28.80$} & \multicolumn{2}{|c|}{$\$ 11.80$} & $\$ 5.13$ & $\$ 6.23$ & $\$ 7.41$ \\
\hline NYISO (West) & \multicolumn{2}{|c|}{$\$ 37.20$} & \multicolumn{2}{|c|}{$\$ 28.80$} & \multicolumn{2}{|c|}{$\$ 11.80$} & $\$ 4.15$ & $\$ 4.41$ & $\$ 3.37$ \\
\hline ISO-NE & \multicolumn{2}{|c|}{$\$ 9.26$} & \multicolumn{2}{|c|}{$\$ 7.07$} & \multicolumn{2}{|c|}{$\$ 7.16$} & & & \\
\hline
\end{tabular}

Darker cell shades indicate real-time markets; lighter are day-ahead markets.

(a) Market clearing price (MCP) for spinning reserve is for the Mid-Atlantic reserve zone in PJM, while regulation MCP is for all of PJM.

$\mathrm{RTO}=$ regional transmission organization

Although details vary, an ancillary service is generally obtained in a day-ahead capacity market, and dispatched in the real-time market. A survey of current wholesale market structure is given in (Ellison et al. 2012). Some independent system operators (ISOs) separately handle regulation up and regulation down. Spinning reserve gets capacity payments, but may not get event payment. Forecasted and unforecasted ramps may be treated differently. It is expected that a large number of small demand resources do not directly participate in the wholesale market. An aggregator handles the wholesale market and presents a much simpler incentive structure for the devices, in a manner analogous to residential customers receiving a simplified electricity rate shielded from wholesale market constructs. This retail structure is very important for TC2 for ancillary services; TC2 might possibly influence this structure as it evolves. TC2 methodology itself may still be applicable in wholesale markets, but our focus in this report is ancillary services in the retail market.

\subsection{Characteristics}

To assemble a portfolio of demand resources (refrigerators, water heaters, clothes dryers, VSDs, etc.) to provide a specific ancillary service, it is necessary to determine the characteristics of the service to be provided as well as those of the devices. The latter are addressed in a later section. In this section, some representative profiles of regulation and spinning reserve are considered. Profiles of ramping are not yet widely available.

\subsubsection{Regulation}

The specific profiles of regulation depend on the ISO, and even for a given ISO on the time of the year and time of day. The goal of regulation is to reduce ACE, but specific implementations vary from ISO to ISO. PJM filters the ACE signal through high- and low-pass filters and procures the two 
components separately. CAISO procures up and down regulation separately. The data for various ISOs shows diurnal as well as seasonal variations, and regulation needs may be higher during the night.

Profiles of regulation requirement every 2 seconds for January 9, 2013, are given in Figure 2.1 and Figure 2.2 for the PJM system. PJM separates the ACE signal into two components using two filters: a low-pass "Regulation A" and a high-pass "Regulation D." Energy neutrality, i.e., a net zero change in energy, over about 15 minutes is often considered a desirable objective for regulation signals but need not be the case, as seen in Figure 2.1 based on data from PJM's website.

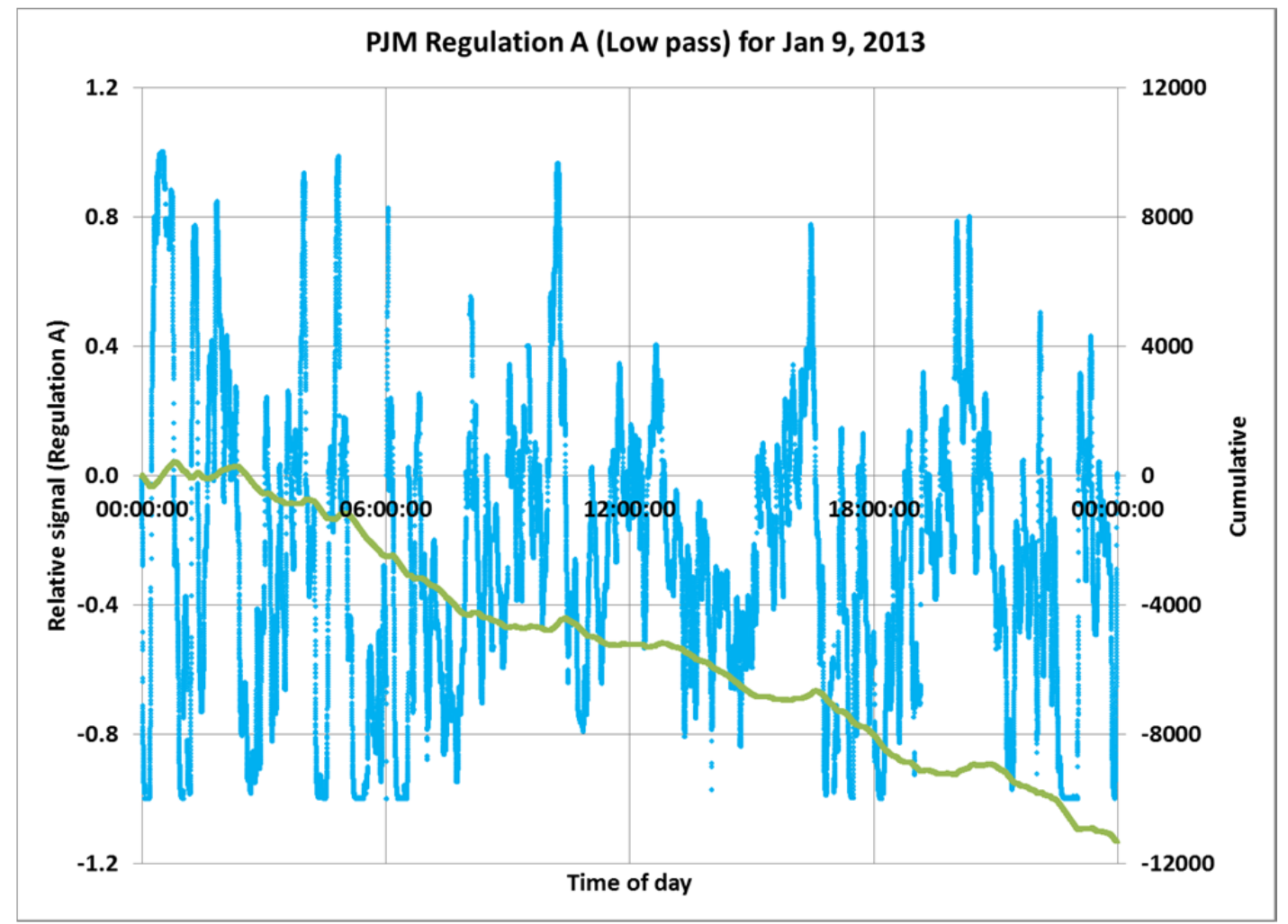

Figure 2.1. Regulation-A Requirement in 2-sec Intervals for January 9, 2013. Blue line represents regulation signal (in some relative units) corresponding to the left axis, and the green line represents the cumulative signal corresponding to the right axis. 


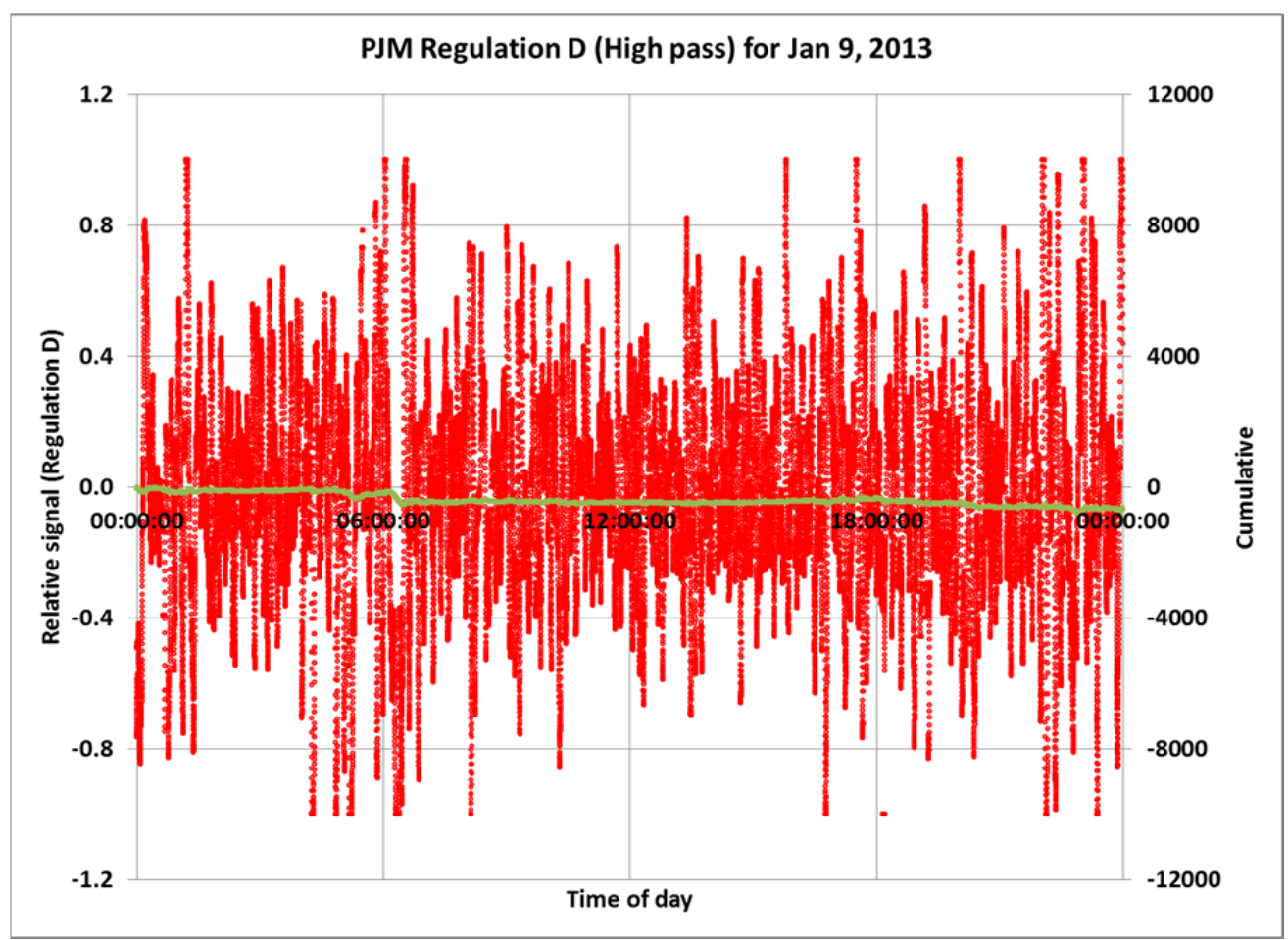

Figure 2.2. Regulation-D Requirement in 2-sec Intervals for January 9, 2013 (from data on PJM website). Red line represents regulation signal corresponding to the left axis, and the green line represents the cumulative signal corresponding to the right axis.

Whether or not energy neutrality exists can impact the consumer and the feasibility of demand resources providing regulation. For example, a water heater accumulating excessive negative values can result in the water temperature being too low. Some combinations of devices and controls may not be able to accumulate positive values: a water heater with a controller that can only turn it off if it is on has no means to increase its stored energy beyond what the thermostat allows. How the regulation signal can be decomposed and devices controlled to provide both regulation up and down is discussed in Section 7.0 on Control.

The quality of regulation provided by a device or combination of devices is determined by how closely the signal is followed. Some generators are not able to adjust quickly. Sometimes the ACE signal may be intentionally damped to reduce movement and direction changes of the generators. PJM's separation of the regulation signal into $\mathrm{A}$ and $\mathrm{D}$ allows them to better match the regulation requirement with the characteristics of the generators. In Figure 2.3 (given in TESA 2010), we can see the difference between the ACE signal and regulation deployed during a test day in the Electric Reliability Council of Texas, Inc. (ERCOT) system:

- Regulation deployed remained in one direction (up or down) for 20 minutes on average, with a maximum of 94 minutes; ACE over the same test period remained in one direction an average of only 2 minutes, with a maximum of 24 minutes.

- Instantaneous ACE value was between -500 MW and $400 \mathrm{MW}$, while the actual regulation deployed was between $-700 \mathrm{MW}$ and $1000 \mathrm{MW}$. 
These differences are attributed to intentional damping of the ACE signal. Although ERCOT system has some atypical features, it still highlights the desirability of fast response. Some demand resources can respond rapidly and can be dispatched without such damping.

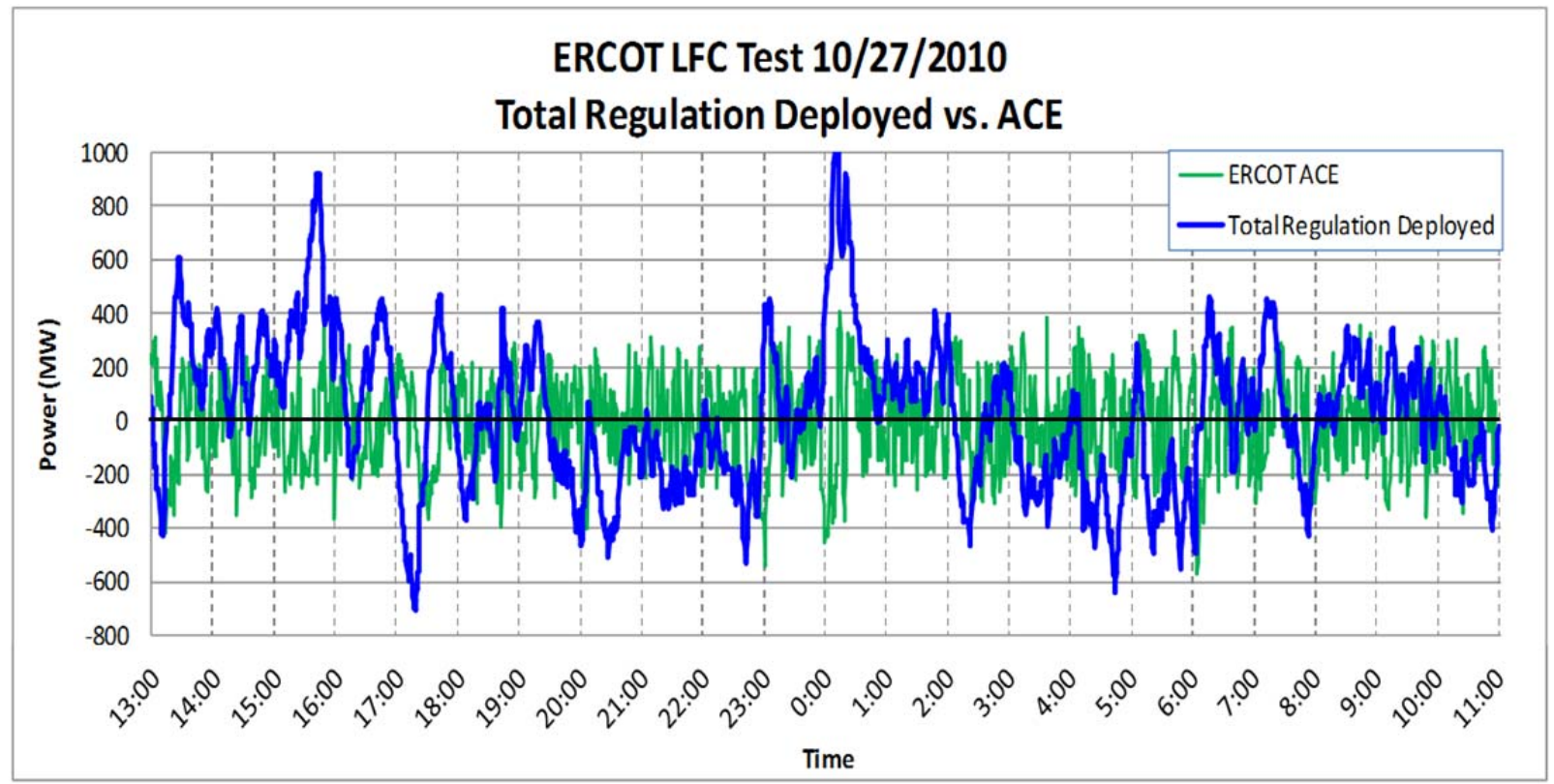

Figure 2.3. ACE Signal and Total Regulation Deployed by ERCOT on October 27, 2010

\subsubsection{Spinning Reserve}

Spinning reserve is often related to system load, and so has somewhat similar characteristics as shown in Figure 2.4 from Amjady and Keynia (2010). 

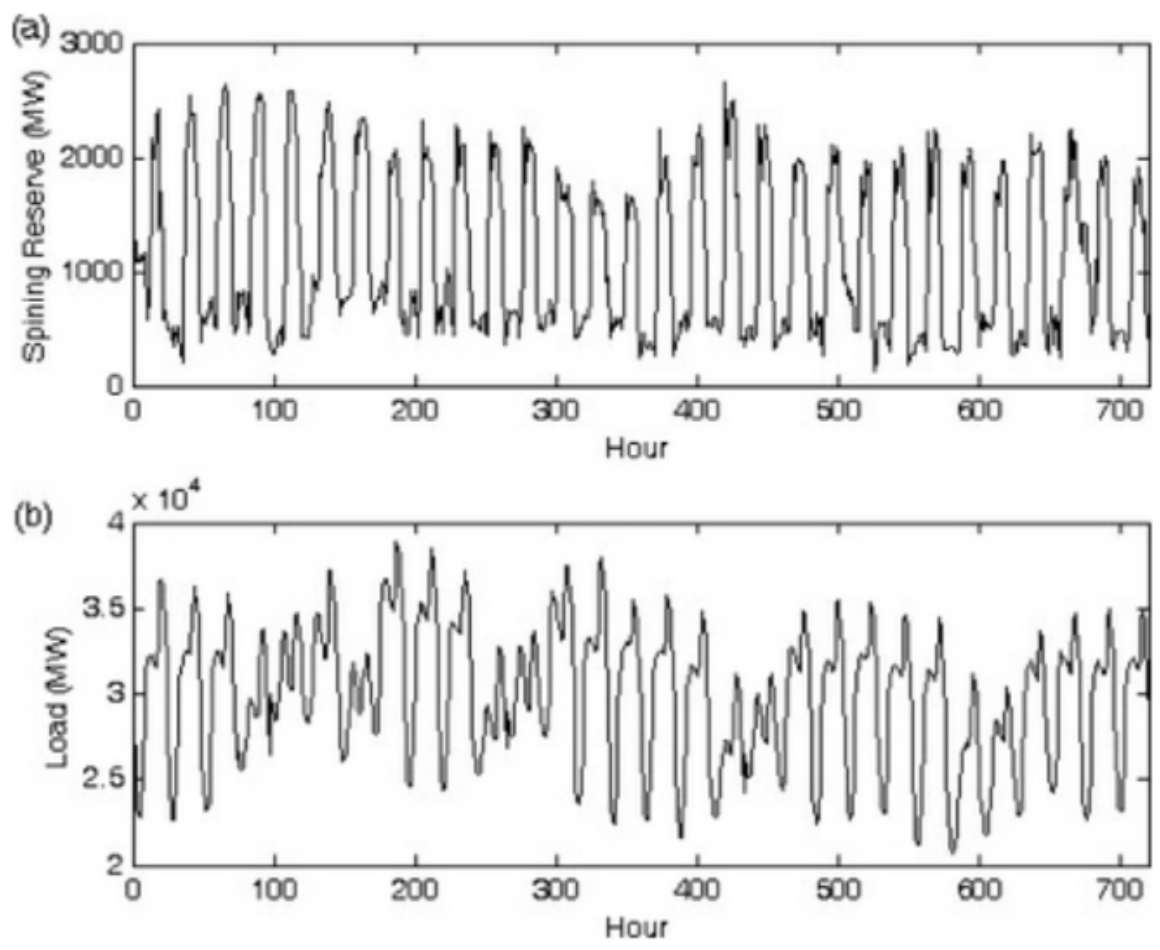

Figure 2.4. The PJM Electricity Market in September 2006: (a) Spinning Reserve Capacity Requirement and (b) System Load. Note the units on the y-axis.

\subsubsection{Ramping}

The basic problem addressed by ramping is the following. Approximately 15 minutes ahead of time, the ISO commits the generation units that are to provide the power to meet the forecasted load. Approximately 5 minutes ahead of time, dispatch instructions are given. Suppose that because of wind and solar variability, the forecast error is large enough such that the units committed do not have enough ramping capacity to meet the load. Then the ISO has to acquire the difference in the higher-priced regulation market, or in some cases purchase energy priced not by economic bids but by penalties. This can be avoided if the ISO can acquire the required megawatts change over the interval ( $\sim 5$ minutes) in a ramping market through economic bids, day-ahead and real-time. A description of the CAISO service that is being planned for rollout can be found in Abdul-Rahman et al. (2012). Ramping capacity is acquired ahead of time. The bids are to provide a specific amount of MW change over $\sim 5$ minutes; both ramping up and ramping down capacities are acquired. If a need for ramping arises, it is dispatched in real time. Demand resources can be fast-acting and are well suited for this service. 


\subsection{Hierarchical Control}

TC2 is envisioned as an element of hierarchical control of the electrical grid. A brief explanation of this hierarchy as well as an explanation of TC2 as implemented in several demonstration projects by PNNL is given below. This will help clarify where TC2 for ancillary services fits in this scheme.

The electric power industry has undergone a fundamental restructuring over the past 30 years, transforming from a regulated to a market oriented system. Restructuring has entailed unbundling of vertically integrated organizations into independently managed generation, transmission, and distribution systems. As a result, electric power markets have been divided into wholesale and retail systems that interact according to a well-defined, albeit ad hoc design.

The wholesale power market design proposed by the FERC in its April 2003 white paper (FERC 2003) encompasses the following core features: 1) central oversight by an ISO; and 2) a two-settlement system consisting of a day-ahead market supported by a parallel real-time market to ensure continual balancing of supply and demand for power. The objective of an ISO or a regional transmission organization (RTO) is to ensure that supply equals demand at every instant, while maintaining system security and reliability and minimizing the total cost of serving the system demand. Optimization is performed on multiple time scales. The day-ahead settlement system is a pure financial market for generators and load-serving entities to create financially binding operating schedules. The real-time energy market allows for the physical exchange of power and addresses deviations between actual real-time conditions and contracted day-ahead agreements. The ISO solves security constrained unit commitment (SCUC) and security constrained economic dispatch (SCED) problems in both day-ahead and real-time markets to determine cleared supply and demand and corresponding locational marginal prices (LMPs), which are reported to market participants. Additionally, to maintain operational balance at any given instant, the ISO runs a balancing reserve market in parallel with the energy markets to calculate the cleared reserve capacities and the corresponding reservation prices. A survey of current markets can be found in Ellison et al. (2012).

Retail markets have not gone through such a restructuring process. Hence, there is limited participation by distributed assets in wholesale markets through aggregators and no direct participation by smaller assets at all. However, this can be expected to change with accelerated deployment of new "smart grid" infrastructure such as digital meters and advanced distribution control systems under the Smart Grid Investment Grants. Additionally, FERC Order 755 now requires grid connected short-term storage devices to be treated equitably as conventional generation units when providing regulation services (FERC 2011a). Similarly, FERC Order 745 requires energy payment of demand response resources at nodal LMPs (FERC 2011b). As a result, a number of wholesale markets now allow limited participation of distributed assets in energy markets, usually to meet peak load reduction or provide emergency services for large-scale demand response programs that serve commercial and industrial users. Feeder level resources still do not participate in wholesale markets, except when provided by demand response aggregators and a limited number of pilot/demo projects (e.g., the Olympic Peninsula Demonstration (Hammerstrom et al. 2008), and American Electric Power (AEP) gridSMART (Widergren et al. 2012)). In order to realize the vision of an integrated demand response system at the wholesale level, it will be necessary to consider market design changes, the development of a more fully fledged system of retail markets, and an integration of the two that provides suitable incentives for participation by distributed assets. 
There are two key elements to any proposed infrastructure that will facilitate smooth and reliable operations. The first is inter-scale infrastructure that allows devices at various levels to cooperate in determining the efficient allocation of the available resources. The second is a multi-temporal infrastructure that allows devices to shape the allocation they have received within the time horizon in which it is allocated.

The inter-scale infrastructure addresses resource allocation and is used to reconcile supply resource constraints with demand requirement (e.g., feeder constraints versus consumer comfort settings at the retail level). This is accomplished by using real-time prices, such as was demonstrated in the Olympic Peninsula GridWise Demonstration project (Hammerstrom et al. 2008), and is also employed by AEP in the Northeast Columbus gridSMART demonstration project (Widergren et al. 2012). These systems establish retail markets that discover the price at which supply equals demand at each feeder in the distribution system given the current day-ahead prices and prevailing conditions on the feeder and in the homes equipped with price-responsive devices. The Pacific Northwest Smart Grid Demonstration Project (PNWSG) (Battelle 2013) uses a variant of this design for resource allocation that relies on mid-term forecasting usage instead of committing to short-term usage. The system also substitutes an index for a price to avoid some of the adverse misconceptions associated with markets in an area that has none at present. The PNWSG project also differs from the AEP gridSMART project in the way the formulated signal is presented to the devices.

The inter-scale structure is shown in the vertical dimension of Figure 3.1. It consists of device, feeder, area, and system (ISO/RTO) structures. The interaction of device level agents with the feeder management system is facilitated through the newly formulated retail markets, while the area level interacts with the ISO/RTO in the wholesale market. The inter-temporal infrastructure is shown in the horizontal dimension and consists of day-ahead market ( $24 \mathrm{~h})$, real-time market ( 5-15 min), and near-instantaneous ( $\sim \mathrm{sec})$ balancing operations.

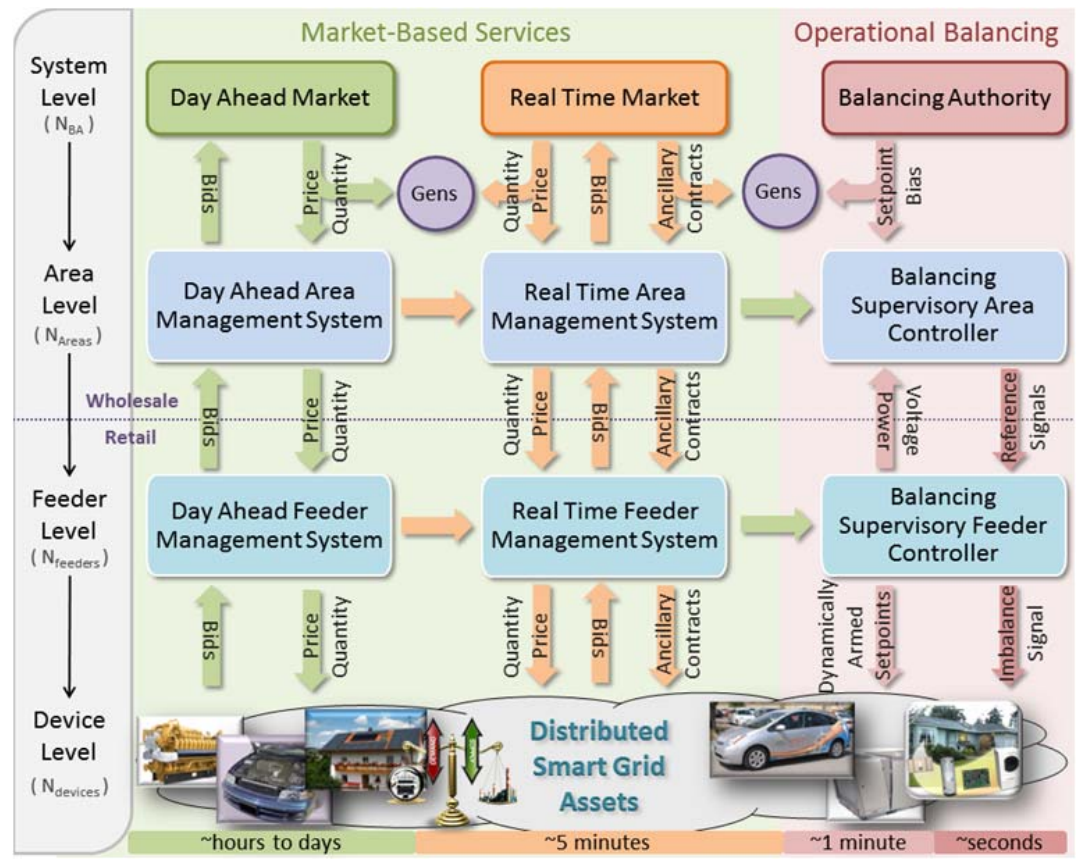

Figure 3.1. Hierarchical Control of Electric Interconnections (Source: Pacific Northwest National Laboratory) 


\subsection{Market-Based Services}

Current market structures do not support a level playing field for distributed assets when compared to conventional generation. The proposed paradigm seeks to create an equitable market mechanism for coordinating and controlling all system assets through a distributed, self-organizing control paradigm that protects customer choice but encourages and coordinates participation. This is the purpose of the so-called "transactive" paradigm. Distributed smart grid asset participation in the wholesale market must be coordinated through a hierarchical architecture of nested market mechanisms. This requires the design of retail markets, but leaves the actual functional control at the device level. This also allows loadserving entities (LSEs) to play their natural role as a resource aggregator in the retail markets and paves the way for independent third party aggregators to develop optimal portfolios to sell to the utilities.

This does not necessitate complete structural changes to current ISO/RTO day-ahead and real-time structures (system level). Rather it complements them by providing institutional mechanisms that integrate retail and wholesale markets using continuous feedback controls. At each of the hierarchical levels (feeder and area), available resources - whether demand or supply, whether energy, capacity, or ancillary services - are aggregated from the level below while considering local constraints, such as energy allocations, capacity limits, and ramping reserves. Device level bids are aggregated by feeder level management systems while applying local constraints by clearing retail capacity markets such as those demonstrated in the Olympic Peninsula GridWise and AEP gridSMART demonstrations.

The feeder level bids are then cleared by the area level market, which submits an aggregated or residual bid into the ISO/RTO wholesale market. Conversely, the area and feeder markets then receive the cleared price and dispatch quantities from the ISO/RTO, which are eventually passed down to the end-use customers. This forms a feedback mechanism for a closed-loop, multilevel optimization problem that engages distributed assets in the wholesale market.

The same structural formulation is applied in both day-ahead and real-time markets. The main difference between day-ahead and real-time markets is the formulation of agents' optimization problems and the source of the information needed to formulate a bid - each bid uses allocations of quantities from longer-term markets.

\subsection{Device-Level Controls}

At the lowest level, devices use price and other information to autonomously determine appropriate actions and apply their own constraints to local control processes. In demonstrations of this approach in the Olympic Peninsula GridWise and AEP gridSMART projects, heating, ventilation, and air conditioning (HVAC) loads responded to changes in normalized price by adjusting the thermostat set point utilizing smart thermostat and smart-meter technology, as illustrated in Figure 3.2. These devices bid the price point for their on/off decision as well their power quantities into a retail market. The price point is a function of the difference between the desired air temperature and the current air temperature and the power quantity is a function of recent metering. Customers are actively engaged with a simple user interface that allows them to choose how much demand response they provide from a range between "more comfort" and "more economic" with a simple slider control. This gives consumers the choice to determine the level of market interaction. They can always override the response by either changing the 
bid response curve or removing the device from the market altogether, provide they are willing to pay potentially higher prices were they to occur. This approach protects customer choice while continuously rewarding participation.

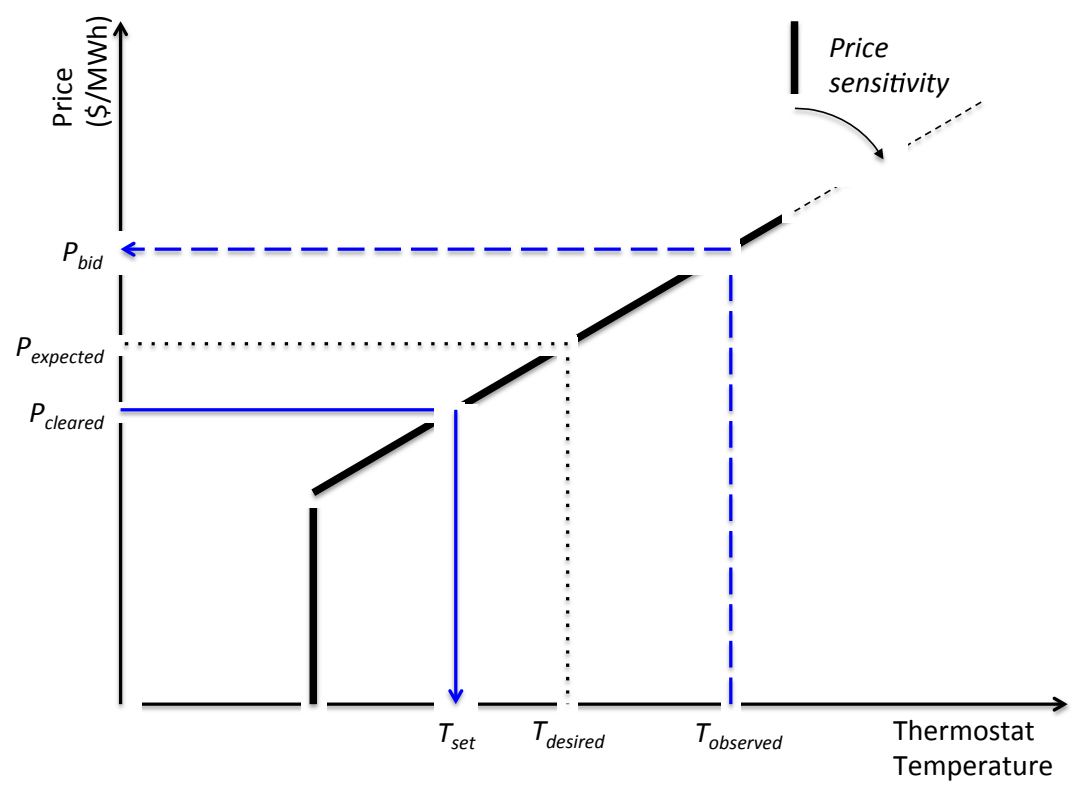

Figure 3.2. Device Control with Price-Based Bid Feedback in the cooling season

Similar device bid-and-response mechanisms must be created for other distributed assets, including distributed storage, distributed generation, and smart appliances. Ongoing work supported by the U.S. Department of Energy's Office of Electricity and General Electric Appliances (Fuller et al. 2013) showed the benefits of multi-objective controls for distributed assets for a wide range of devices. The end result would be an environment and a set of rules for participation where vendors can create additional bidding and control strategies, depending upon the goals of the customer, ranging from relatively simple to highly complex optimization routines or predictive algorithms. Design of device level controls and bidding strategies forms the basis for their participation in retail markets.

The goal of this project is to develop a TC2 method for ancillary services following the basic ideas presented above. The market structure and control discussed later are specific to ancillary services. 


\subsection{Demand Resources for Ancillary Services - Barriers}

The current status of ancillary services and barriers to increased participation by demand resources have been considered (Kirby 2006; DOE 2011; Pratt and Najewicz 2011; Perlstein et al. 2012; MacDonald et al. 2012; Cappers et al. 2013; De Martini 2013; Shogren 2013). Considerable progress has been made in facilitating the participation of demand resources especially large commercial and industrial demand resources. Some hurdles remain and some of the ones discussed in Kirby (2006) are relevant and are summarized below:

- Creation of aggregators

An ensemble of small loads has the ability to provide high quality ancillary services, but the loads are not likely to participate individually. An aggregating entity is needed to create a suitable portfolio of assets. Such an entity may be a commercial aggregator or the assets may be regulated to provide the services, possibly through utility rates.

- Enabling hardware and software

Appliances such as refrigerators, water heaters, HVAC systems, and clothes dryers should have the technical ability to participate in the market. Aggregating entities need the appropriate tools to acquire the right amount of services at the right times.

- Capacity markets

Some ISOs procure ancillary services months ahead through forward reserve auctions. Demand resources may not be able to make commitments so far in advance.

- Co-optimization of energy and ancillary services

An ancillary service bid that did not clear the ancillary market may be automatically included in the energy market by some ISOs and possibly dispatched in the energy market. Some demand resources may only wish to participate in the ancillary market. Furthermore, some demand resources can provide services at a low cost initially, for a period on the order of 30 minutes. If the contingency lasts for a much longer period, the cost of providing the service may go up and the available quantity may go down. This situation is not encountered in generators and the current systems may not be able to accommodate such demand resources.

- NERC rules

The rules and sometimes even the definitions are primarily geared to generation. Demand resources have not received a treatment comparable to that for generators.

- Regional variations

Some regions may not even allow demand resources in the spinning reserve market. Some may require spinning reserve to be able to provide services for a much longer period than others. The difference may not be significant for generators but would be crucial for demand resources. 
- Measurement and verification

Generation assets consisting of a small number of large generators have sophisticated communication, control, and monitoring systems with dedicated staff. A large number of small demand resources must be handled in a very different manner, possibly through the use of smart meters and multipurpose communication infrastructure. Such systems and rules for engaging them have not yet emerged.

In summary, demand resources are able to provide reliable ancillary services, but new market designs are needed to enable their full participation. Even after such markets are designed, systems are needed to manage, coordinate and control the demand resources. The goal of this project is to present one such system: TC2. 


\subsection{Availability and Load Shapes}

In this section, we discuss the general characteristics of individual devices and an ensemble of devices to provide various ancillary services. The devices considered are refrigerators, water heaters, clothes dryers, and VSDs. There is a great deal of heterogeneity even within each device type. The capabilities of the devices, especially their ability to interact with the grid, are rapidly evolving. A feature-rich device can have superior control capabilities but can also be expensive. The value generated per device by ancillary services and the cost of features will govern the evolution of the capabilities. We will make some assumptions about the capabilities of the devices. Development of enabling technologies and policy decisions can modify the validity of the assumptions and subsequent discussions.

- Refrigerators and water heaters are controlled thermostatically. If a device is on, it can be turned off. If it is off, it can be turned on by modifying its thermostat setting (within certain limits). We will actually consider methods that allow relaxing this assumption.

- VSDs and water heaters can provide regulation by responding to regulation signals every few seconds. An individual VSD can follow a regulation signal, but a single water heater cannot, unless it is equipped with the ability to modulate its energy use. We assume it does not have that ability. But an ensemble of water heaters with a well-designed control strategy can provide high quality regulation.

- If our specifications call for it, a device can provide its status: on or off. Additional capabilities such as more detailed status (e.g., defrost) or where it currently is in its duty cycle are not available.

- Clothes dryers opportunistically provide spinning reserve or ramping up services.

Spinning reserve: Any resource that is turned on can provide this service if it can be turned off or, in the case of VSDs, slowed down. Thus, refrigerators, water heaters, clothes dryers, and VSDs all can provide spinning reserve. Clothes dryers can only bid opportunistically if they are on. Lock-out issues, such as the ones for refrigerators discussed later in the section, should be addressed. Following the event, the devices need to return to pre-contingency condition. This will increase the load following the event, and the return should be staged in such a way that all devices are not released at once. The roles of the aggregator and the ISO in managing the post-contingency load increase should be assigned.

Ramp up: This is similar to spinning reserve except that the service is required far more frequently. All the considered devices can provide this service.

Ramp down: This requires increasing the energy use. VSDs, refrigerators, and water heaters have this ability. Clothes dryers may not have this ability.

Regulation up/down: This requires responding to a regulation signal every few seconds. A VSD is well suited to provide this service; an individual VSD can follow the regulation signal (within its limits). If a high quality control algorithm is developed, an ensemble of water heaters can be staged to follow the regulation up signal. Using water heaters for regulation is demonstrated in Steffes (2011); using refrigerators for regulation is demonstrated in Bloor et al. (2009).

In Olsen et al. (2013), the authors define three terms: 1) Sheddability: for a given end use, what percentage of load "can be shed by a typical demand response strategy, assuming adequate 
communications, control and incentives exist;" 2) Controllability: for a given end use, what percentage of the load "is associated with equipment that has the necessary communications and controls in place to trigger and achieve load sheds/shifts;" and 3) Acceptability: for a given end use, what percentage of the load "is associated with equipment or services that are willing to accept reduced level of service in a demand response event, in exchange for financial incentives," and they combine them with loads in the form Loads $\times$ Sheddability $\times$ minimum (Controllability, Acceptability) to determine availability. They considered a number of devices and developed the availability for the Western Interconnection. The availability is sensitive to the specific assumptions, but broadly speaking, demand resources have the potential to provide much of the ancillary services. Demand resources should therefore be included in the mix of devices providing ancillary services. Some devices such as refrigerators and water heaters were not included in Olsen et al. (2013). Some ancillary services, (for example, absorbing higher-than-forecast renewable generation), require demand resources to respond by increasing, not shedding, their energy use. Knowing the load shapes, however, the requirement on an ensemble of devices to provide the required service can be established. In this report, we will consider some load profiles for the devices of interest. We will not consider factors needed to determine availability from load profiles for different regions of the country; such factors require detailed data and are subject to the uncertainties of various assumptions.

Let us consider the energy use profiles of different types of devices averaged over a representative sample of each type of device. How representative a sample is depends on the location (especially for weather dependent profiles) and can change over time due to brand, features, age, and operations, but the following profiles provide a useful starting point. These are typically obtained by submetering circuits within a suitably large and representative number of homes. Examples can be found in Ruderman et al. (1989), Hendron and Engebrecht (2010), and ELCAP (2013). Such data collection efforts are time consuming and expensive. Non-intrusive load monitoring, i.e., disaggregation of end use from learning algorithms such as pattern recognition and rules, is another option; see for example Powers et al. (1991), Margossian (1994), and Marceau and Zmeureanu (1999). The data needs to be updated to capture changes due to technology and consumer behavior. Such updating has been made to the graphs below.

Figure 5.1, Figure 5.2, and Figure 5.3 show typical load profiles for water heaters, refrigerators, and clothes dryers, respectively. Figure 5.4 shows heating and cooling loads from the Northwest. These figures are based on Pratt et al. (1989). The updating for technology changes is based on data from Residential Energy Consumption Survey (EIA 2009). Figure 5.5 shows a typical cooling load profile from a hot and humid region.

HVAC load served by VSDs is highly variable depending on the HVAC type, geographical location, and facility type. A sample profile for a residential building in the Northwest is given in Figure 5.4 and one for a medium sized commercial building in a hot and humid climate in Figure 5.5.

Profiles of VSD fans are highly dependent on facility type, occupancy hours, weather, and control strategies. An office building on a weekday may have a profile like that shown in Figure 5.6, which shows that the fans are turned on around 5 a.m. and run initially at high speed and then at a relatively steady medium speed, and are turned off at 6 p.m. Figure 5.7, adapted from Hao et al. (2012), shows a very different profile for a university campus building. 


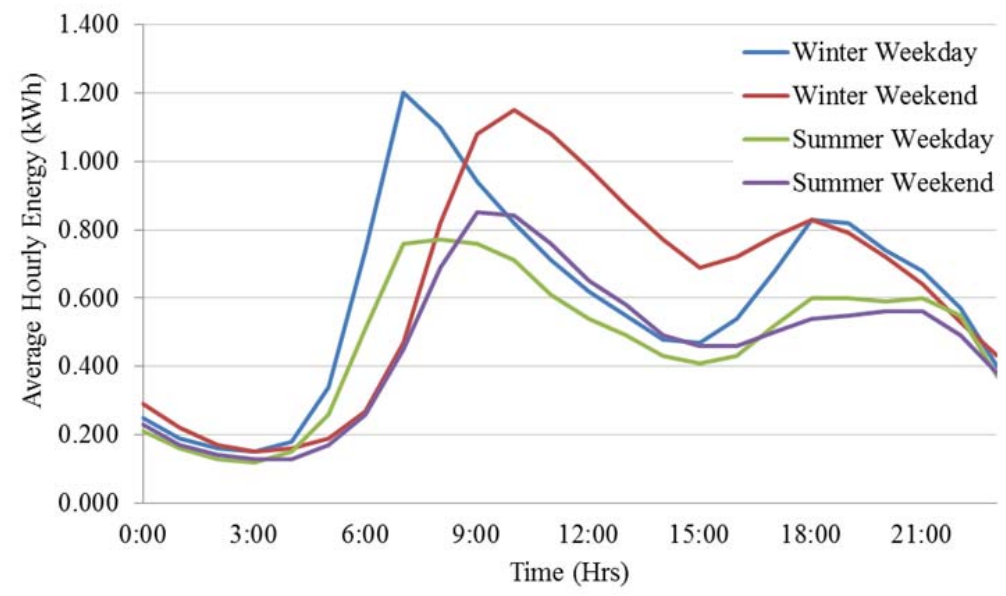

Figure 5.1. Typical Load Shapes for a Water Heater Extracted from ELCAP Data

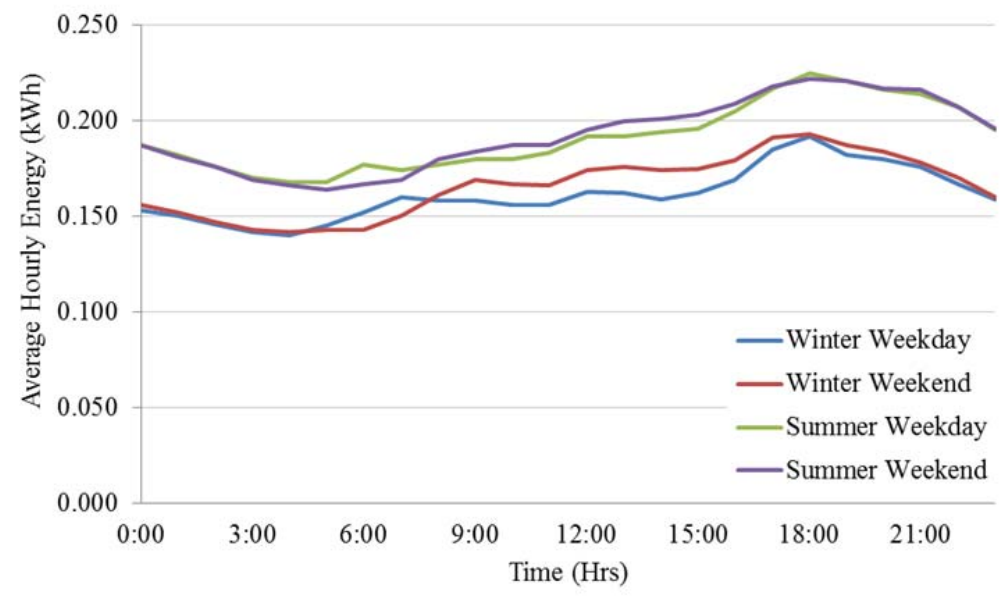

Figure 5.2. Typical Load Shapes for a Refrigerator Extracted from ELCAP Data (Pratt et al. 1989)

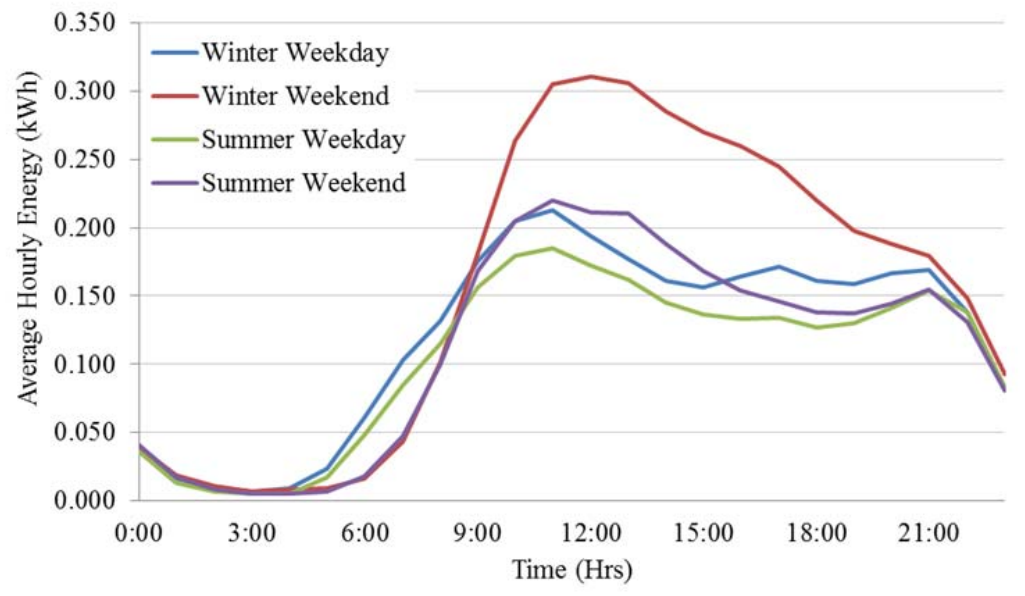

Figure 5.3. Typical Load Shapes for a Clothes Dryer Extracted from ELCAP Data (Pratt et al. 1989) 


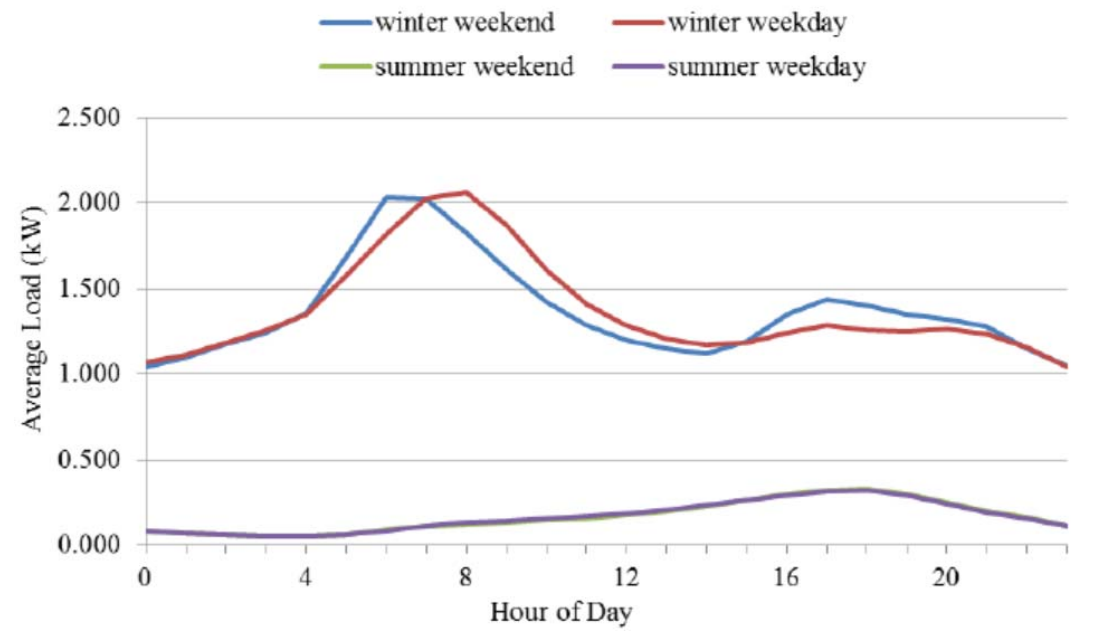

Figure 5.4. Typical Load Shapes for Heating and Cooling Extracted from ELCAP Data

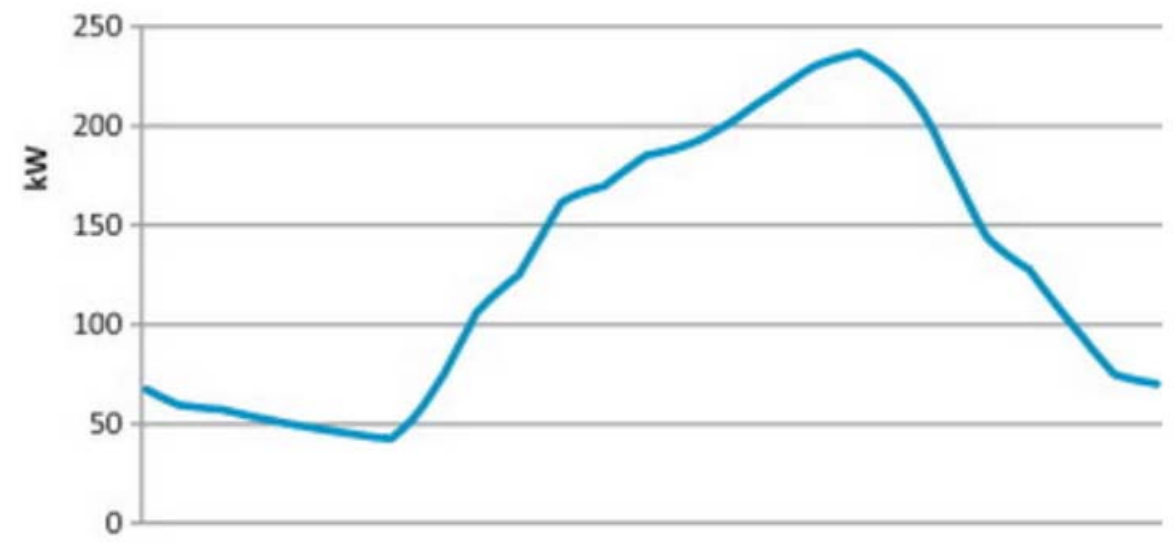

Figure 5.5. Typical Daily Cooling Load as a Function of Time for a Medium Size Office Building in a Hot and Humid Climate. The horizontal axis represents a day.

Certain general features about availability can be inferred from the load profiles. Availability at night is low for water heaters, clothes dryers, and fans in commercial buildings, whereas refrigerators tend to provide a more steady resource.

A device can have multiple modes of operation. Consider a refrigerator. The largest power and energy demand of a refrigerator is the compressor which cycles on and off to maintain the internal air temperature near a preset value. In some models, the compressor may be dual speed, low for normal operations and high to precool the refrigerator before a defrost cycle. In addition to the additional compressor load, the defrost cycle activates heaters around the cooling coils to melt accumulated ice on the coils. In addition to this main process, there are a number of subprocesses, depending upon model, make, and age of the equipment. These may include anti-sweat heaters for eliminating moisture from the outer shell, fans for moving air from one compartment to another, ice makers, lights, and power electronics. While very dependent on size of unit, manufacturer, efficiency rating, etc., Table 5.1 shows average or rough approximations of the power demand of standard processes within a refrigeration unit. 


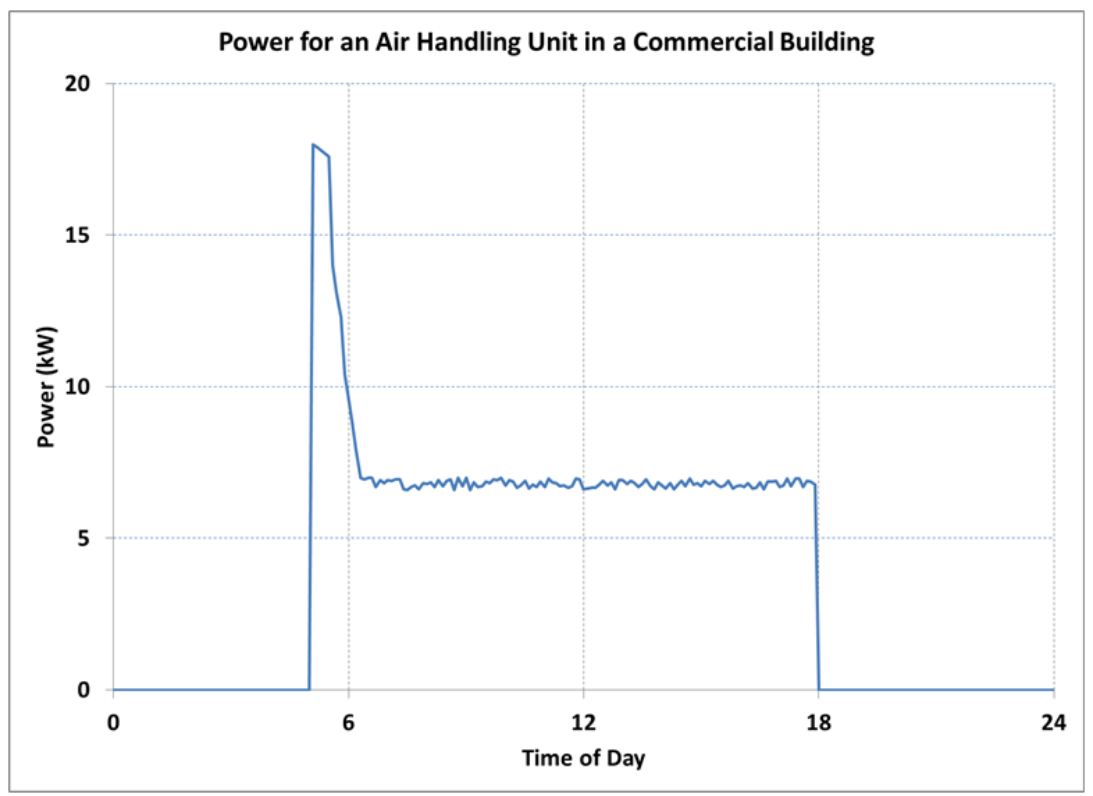

Figure 5.6. Power Draw from a VSD Supply Fan in a Commercial Building on a Typical Weekday

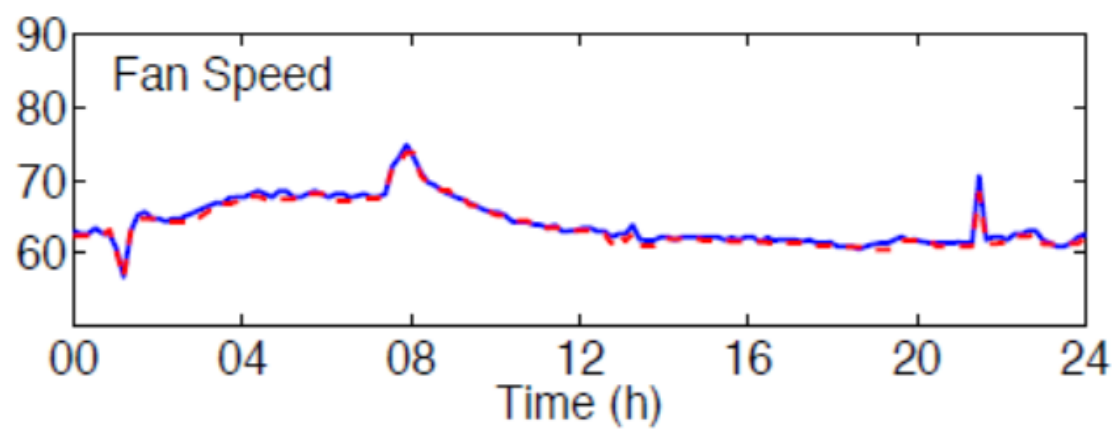

Figure 5.7. Profile of the Fan Speed of an Air Handler with VSD over a 24-hour Period (adapted from Hao et al. 2012)

Table 5.1. Approximate Demand of Individual Processes within a Residential Refrigerator

\begin{tabular}{lc}
\hline & Demand (Watts) \\
\hline Compressor (low) & $\sim 100$ \\
Compressor (high) & $\sim 150$ \\
Defrost & $\sim 400$ \\
Sweat Heaters & $\sim 10$ \\
Ice Maker & $\sim 100$ \\
Other (lights, fans, power electronics, etc.) & $\sim 25$ \\
\hline
\end{tabular}

To a certain degree, consumer interaction with the appliance affects its behavior, particularly in that the duty cycle of the compressor and the frequency of the defrost cycle increase as consumers open the door more often or place more hot food into the cavity. This can be seen in Figure 5.2 as the daily load shape is roughly uniform versus time of day, with a slight increase in demand during the dinner period. 
This may be useful, as this means that the amount of resource available from refrigeration is somewhat independent of time of day.

The compressor cycle, and to a certain degree the defrost cycle, is not interruptible. To do so on a consistent basis without taking into consideration the current runtime of the compressor may cause damage or excessive wear and tear on the units. Consequently, the entire unit cannot be used for performing ancillary services by turning the unit off and on. Therefore, for the purposes of this discussion, it will be assumed that the refrigerator is a "smart" appliance with the ability to control the individual processes within the device and ancillary services cannot effectively be performed on retrofitted refrigerators. In addition, it is assumed that this technology is not driven by human interaction and will be, for the most part, automated.

For example, ENERGY STAR Program Requirements Product Specifications for Residential Refrigerators and Freezers - Eligibility Criteria Version 5.0 discusses compliance for demand response (DR) functionality (ENERGY STAR 2013), including a number of energy reduction methods that may be required for refrigerators to be DR compliant. All ice making must be deferrable for a minimum of 4 hours, although longer is acceptable, provided the ice making process has not already been started. Additionally, it is expected that pre-cooling and defrost cycles (Delayed Defrost) can also be deferred for 4 hours providing the cycle has not already begun. For shorter time periods (10-15 minutes), the device must be able to reduce demand by $50 \%$ from baseline operations (note that this does not mean current operations). Comments from some utility sources to these requirements indicate that response for longer events may be on the order of 10-20 W per unit and as high $100 \mathrm{~W}$ per unit for shorter time periods. Studies with GE Smart Appliances indicate that for spinning reserve type events, $\sim 40 \%$ of load may be available for short-term reduction whereas $\sim 30 \%$ may be available for a single regulation event (Fuller and Parker 2012). These studies did not address the ability to increase load.

Future analyses in a simulation environment of the issues arising from multiple states of the devices and their technical capabilities are planned. 


\subsection{Market}

The current ancillary service markets, as mentioned before, are geared toward a small number of large generation assets. A major restructuring of the market is necessary if a large number of demand resources are to be participants. An aggregating entity will shield the homeowners from the complexities of the wholesale market by presenting simplified market constructs. Even in the current markets, where demand participants are a relatively small number of relatively large commercial and industrial loads, an aggregator presents a simplified market structure for the facilities owners. For example, EnerNOC (Endicott 2013) is an aggregator that has three simplified markets in PJM territory in which demand resources can participate:

1. a capacity market - the Emergency Load Response Program - that makes "monthly capacity payments for agreeing to reduce load; energy payments for actual load reductions"

2. an energy market - the Economic Load Response Program - for active reductions based on wholesale energy prices that makes "hourly energy payments for actual load reductions"

3. an ancillary service market for spinning reserve that makes "hourly availability payments for agreeing to reduce load when dispatched." This market requires one-minute interval metering. Capacity payments are made but no event payments are made.

For a large number of demand resources to participate, the retail market should be simplified and the incentives attractive and fair. For example, the ISO may impose a penalty for non-performance on the aggregator, but the aggregator can structure the retail market through incentives but no penalties by making an event payment to homeowners in addition to capacity payments, even if the ISO only makes capacity payments to the aggregator.

The retail market should have the following characteristics:

- It should be simple

- Participation should be entirely voluntary

- Each participant decides at what price s/he is willing to participate.

With these principles in mind, the TC2 energy market projects at Olympic Peninsula and at AEP developed a slider that the homeowner can adjust that translates to a price at which s/he will participate; the current value of the temperature being controlled and thermostat settings influence the bid price. When relevant, (for example, for VSDs controlling a space temperature), a similar strategy can be developed. Minimum fan settings, if any, should be respected. Clothes dryers participate opportunistically when they are on.

Some issues that affect market constructs are now discussed. Some of these may overlap with the control scheme as the two are interrelated.

- A hierarchical approach allows the aggregator to have a retail market that is responsive to the wholesale market, but can operate differently. For example, an aggregator can have 5-minute bids for a retail ancillary service even if its contract with the ISO is for a longer period such as 30 minutes. 
- If a contingency spans multiple bidding periods, the bids from devices for the second and subsequent periods may be influenced by the knowledge that a contingency has occurred. Longer intervals reduce the possibility of such gaming of the system, but shorter bid intervals increase the likelihood that a device that is on (or off) remains on (or off) during the bid interval. The bid interval and performance interval need not be the same. If, for example, the bid interval is 5 minutes and the performance interval is 15 minutes and a contingency arises, the bidding may be suspended during the period of performance.

Let us recall:

- Bid interval: If the auction is conducted every 5 minutes then this interval is equal to 5 minutes.

- Performance interval: If the reserve is called, the device should perform for this interval; it may be and often is equal to the bid interval. As an example, consider a refrigerator providing spinning reserve by being prepared to be turned off. If this interval is 30 minutes for spinning reserve, then in the event this reserve is called, the refrigerator should stay turned off for up to 30 minutes.

Ramping up: This is perhaps the simplest case. The ramping product is being discussed as having a $\sim 5$ minute performance period from the ISO perspective. The retail market can have similar bid and performance intervals. Resource acquisition and dispatch should be considered carefully. Suppose the ramping requirement is to drop the load by $1 \mathrm{MW}$ in 5 minutes. Loads that are currently on and that add up to $1 \mathrm{MW}$ can be turned off (in some staged manner to avoid rapid drop). Some loads that were not on at the beginning of the interval will be on during the performance period; toward the end of the 5 minutes, the effective drop may be less than $1 \mathrm{MW}$. This can be accommodated by acquiring resources totaling an amount suitably higher than $1 \mathrm{MW}$ and dispatching them appropriately. Providing this service impacts the energy in the recovery period following the performance period; it also can affect the regulation requirement, depending on the behavior of the ensemble during the performance period. Although these can be viewed as control issues rather than market issues, they are relevant to the market if the aggregator has to deal with energy and regulation markets in offering ramping service. At least, this information on energy impact should be available to the aggregator/ISO for proper planning. This is really not very different from the generators providing such parameters as minimum start times, ramp rates, minimum loads, and minimum run times.

Ramping down: VSDs, refrigerators, and water heaters can provide this service by increasing their energy use during the performance period. Only refrigerators and water heaters that are currently off can offer this service. The aggregator needs a market for ramping down, separate from ramping up. This is consistent with the wholesale market being proposed by CAISO. Any connection with energy and regulation is similar to that for upward ramping.

An interesting possibility is for refrigerators without the ability to lower their temperature setting or water heaters without the ability to increase their temperature setting to provide ramping down. This is possible if first they have accrued an energy debt and are ready to turn on. This requires revolving the debt over the devices and needs appropriate market structures and control. Studies of such features are planned for the future.

Spinning reserve: Currently, the largest participation of demand resources, albeit by large commercial and industrial loads, is in this service. A body of experience of ISOs, aggregators, and facility owners/operators exists. Participation by a much larger number of much smaller resources raises 
new issues. A contingency lasts less than 15 minutes on average and occurs infrequently. Demand resources can provide this at a low cost for periods up to about an hour. Short bid and performance periods in the retail market ( $\sim 5$ minutes) make resource acquisition and dispatch generally simpler. However, if the contingency lasts longer than $\sim 5$ minutes, the increased load caused by recovery in the subsequent interval and the continued need to provide spinning reserve service requires acquiring higher resources in the second period. Also the possibility of price hikes by devices in the second period is of concern. One solution is to make bid periods $\sim 5$ minutes, and performance periods $\sim 30$ minutes, and suspend the bidding if a contingency arises.

Regulation: A single VSD can follow a regulation signal, both up and down; an ensemble is simply the sum of these. Water heaters that can be turned on and off quickly can certainly provide regulation. Generally speaking, slow-acting devices such as refrigerators cannot provide regulation. Whether an ensemble of slow-acting devices can be controlled to provide an acceptable quality response to a rapidly varying signal needs further investigation. We can then conclude that VSDs and water heaters are the devices that participate in the regulation market.

Regulation signals are sent at regular intervals of a few seconds (e.g., 4 seconds). It is likely not feasible to have bid intervals of a few seconds. The bid interval may be $\sim 5$ minutes, and the devices have to respond to the regulation signal during the bid period. It is important that the devices bid their status. The ones that are on can provide regulation up, and the ones that are off can provide regulation down. The aggregator can adjust the amounts of regulation up and down procured in each bid period based on historical patterns of regulation.

As discussed in the next section, the regulation signal can be separated into low and high frequency components such that the high frequency signal is energy neutral, and the low frequency component carries energy non-neutrality. If the ISO creates separate markets for these, and the retail market follows suit, then separate TC2 processes can be developed for the two markets. 


\subsection{Control}

In this section a number of control issues to be dealt with in developing a TC2 approach for ancillary services are discussed.

\subsection{Regulation}

Regulation signals are sent in intervals of a few seconds (e.g., 4 seconds) and the devices should respond to these signals. The bid interval is longer ( $\sim 5$ minutes), and between bids the devices should have to respond autonomously and stochastically to the signal. The aggregator may process the signal from the ISO before broadcasting a signal to the devices. Such processing may eventually be done by the ISO itself. Here we consider the processing necessary for proper participation by the demand devices.

\subsubsection{Signal Decomposition}

Historically, power production and ancillary services have been primarily the domain of generators. For regulation, energy neutrality over short intervals of the order of 15 minutes, while desirable, is not essential. The generators can deal with the non-neutrality. It is a bigger problem for demand resources. High frequency variations of regulation, on the other hand, are a problem for generators because they cannot adjust quickly. Some demand resources can adjust quickly, but energy non-neutrality is a problem. An attractive solution is to divide the regulation signal into a high frequency component to be handled primarily by demand resources and a low frequency component to he handled primarily by generators. This is really a refinement of the PJM approach of dividing the regulation signal into a low frequency Regulation-A signal and a high frequency Regulation-D signal to better match the characteristics of the portfolio of generators with regulation requirements. The question of what constitutes low and high frequencies should be revisited when demand resources participate.

Regulation-D signal, while more energy neutral than Regulation-A signal, still has some energy non-neutrality. For illustrating the concepts when demand resources participate, it is sufficient to use Regulation-D signal, and this will be generally referred to as the regulation signal.

Consider the problem of separating the regulation signal into two components: a high frequency component and a low frequency component. We can apply filtering theory for this decomposition. For some applications of filtering theory, the high frequency parts are viewed as noise to be eliminated. In our case, both components are important. Perhaps the simplest and most robust approach is to use an exponentially weighted moving average (EWMA) filter as the low frequency component and the residual as the high frequency component. As is well known, causal filters, EWMA being one of them, introduce a delay in the low frequency component, but this is not a problem for our decomposition. EWMA has a parameter that controls the degree of smoothing. Unlike a moving-average window with a sharp cutoff, EWMA uses all past values with exponentially decreasing weights. The smoothing parameter represents a characteristic smoothing interval. In the following, this interval is chosen to be 30 minutes.

As can be seen from Figure 7.1 and Figure 7.2, the low frequency component carries the energy non-neutrality and is smooth. Figure 7.3 shows the high frequency component that is the regulation to be provided by the demand resources. The low frequency component is eventually carried by the generators. Figure 7.4 shows a magnified view of a part of the low pass signal (blue line) in Figure 7.2. How 
smooth it should be before it can be considered to be a part of load following and how it is transferred to the generator need further investigation.

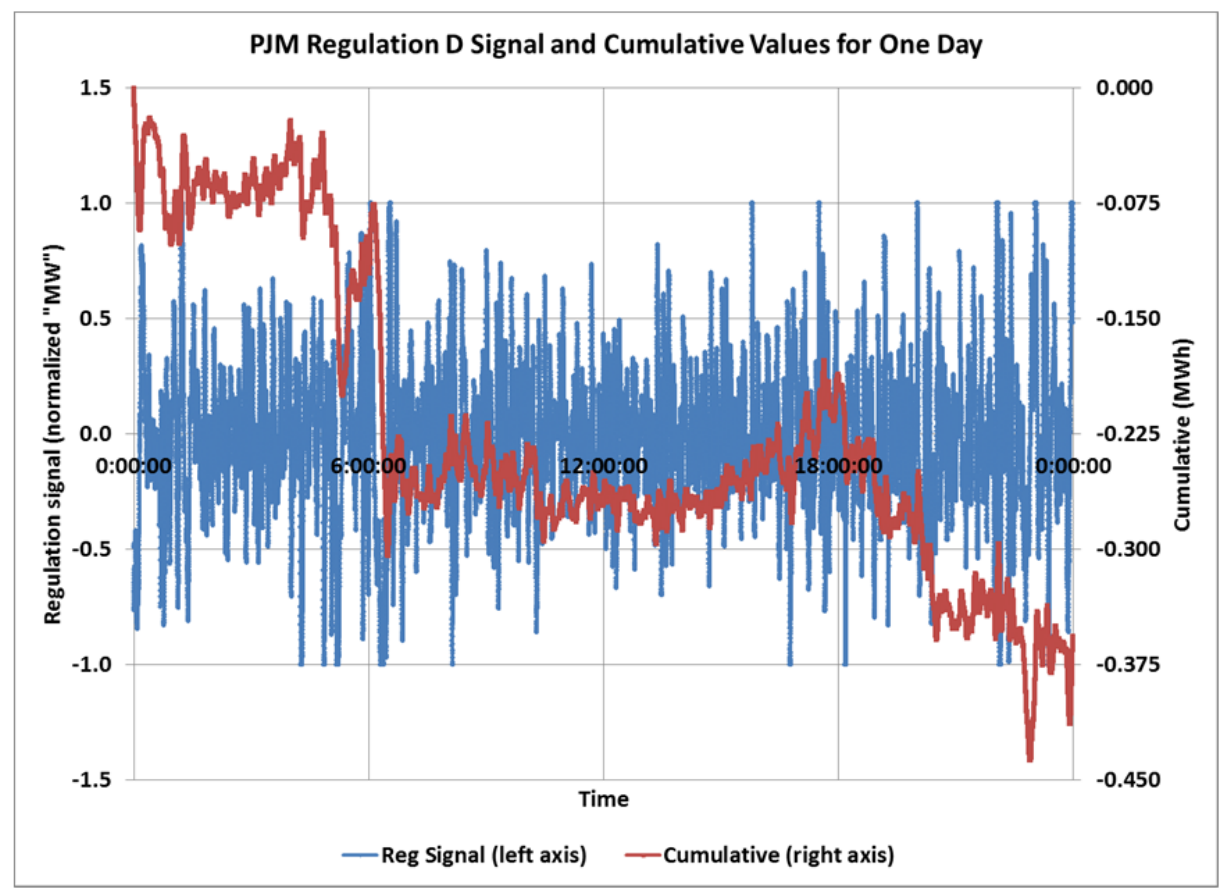

Figure 7.1. PJM Regulation-D Signal (left axis) and the Cumulative Value (right axis). The average is drifting down. Note the black time labels.

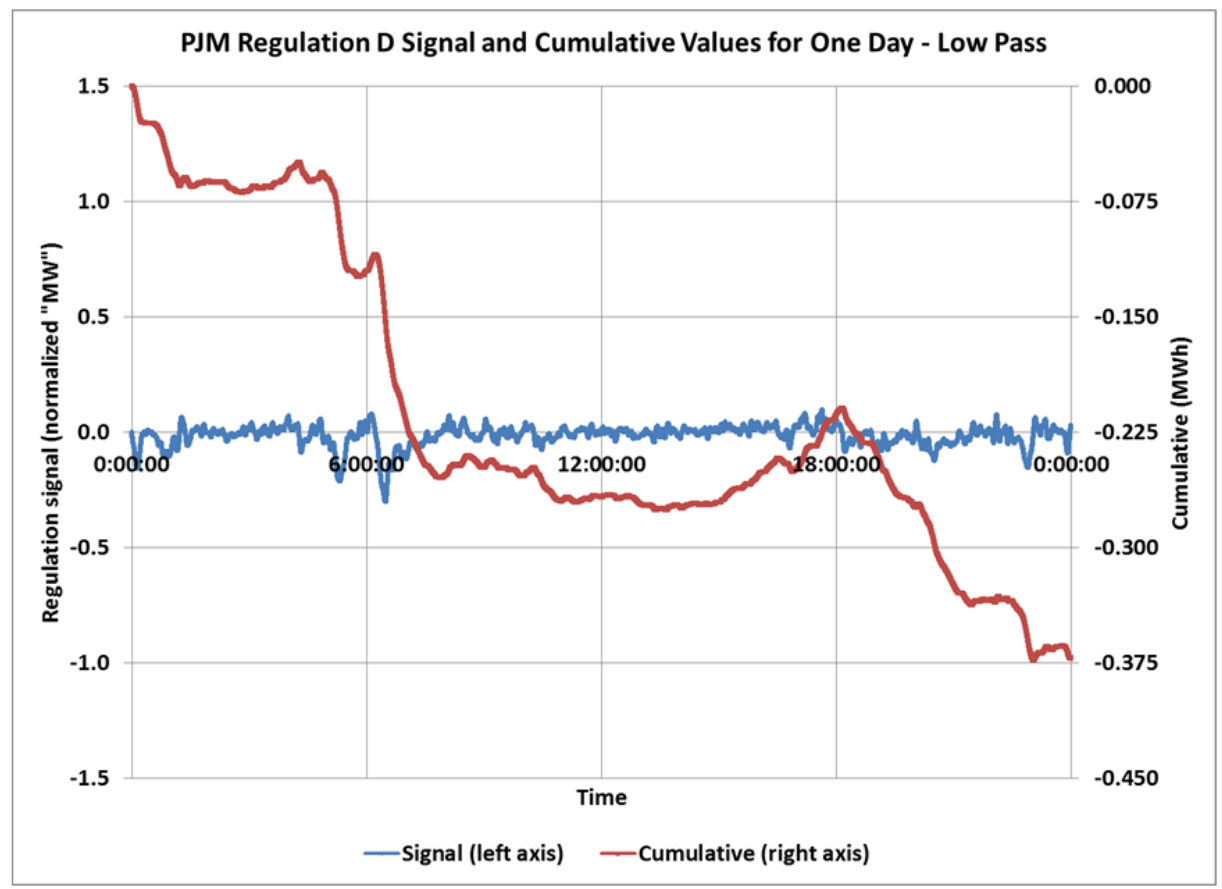

Figure 7.2. Low Pass Signal (exponentially weighted moving average, smoothed over $\sim 30$ minutes) and its Cumulative Value. 


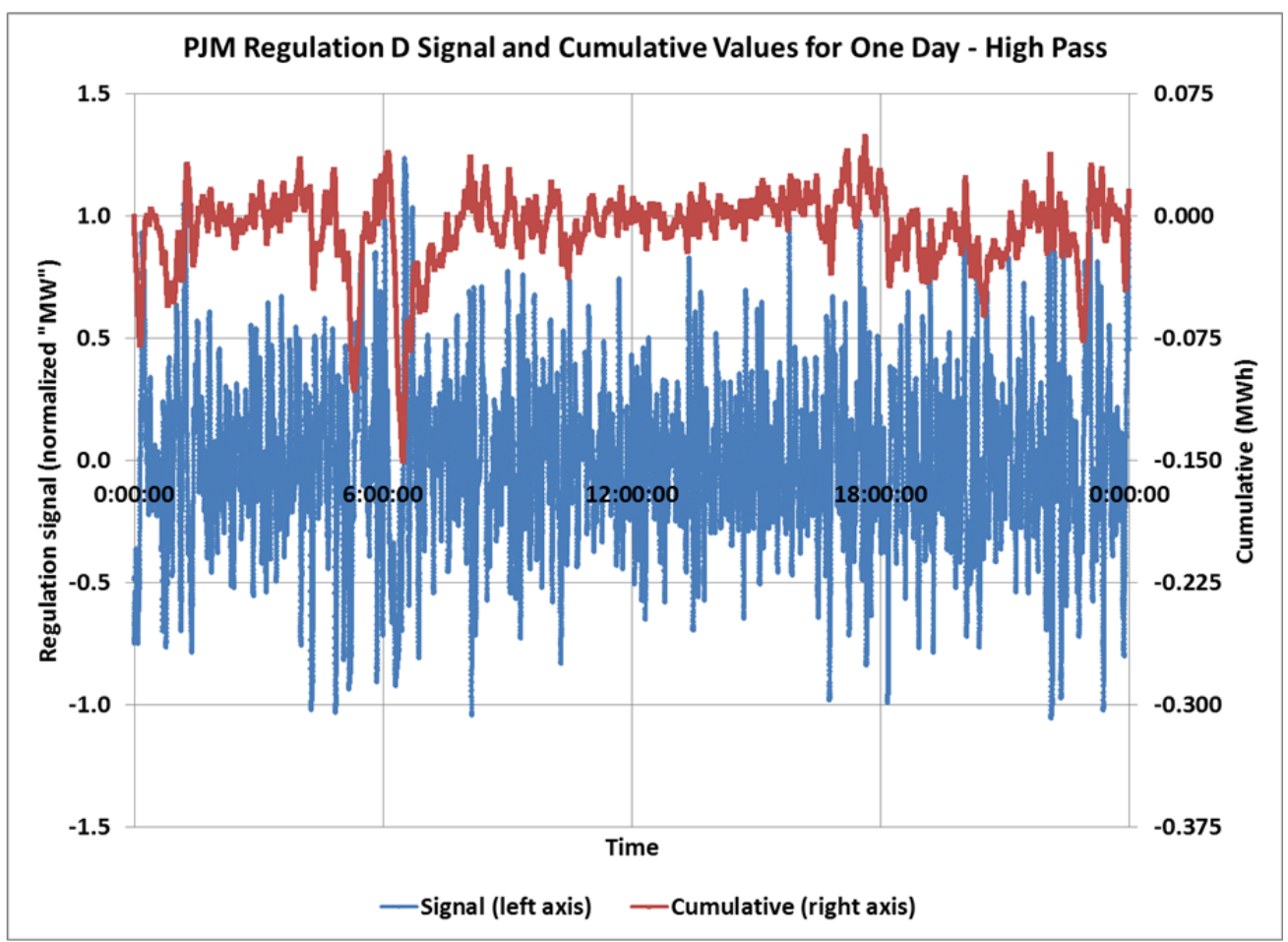

Figure 7.3. Regulation Signal with the Low Pass Component Subtracted. This is quite energy neutral. (Note the zero on the secondary y-axis.)

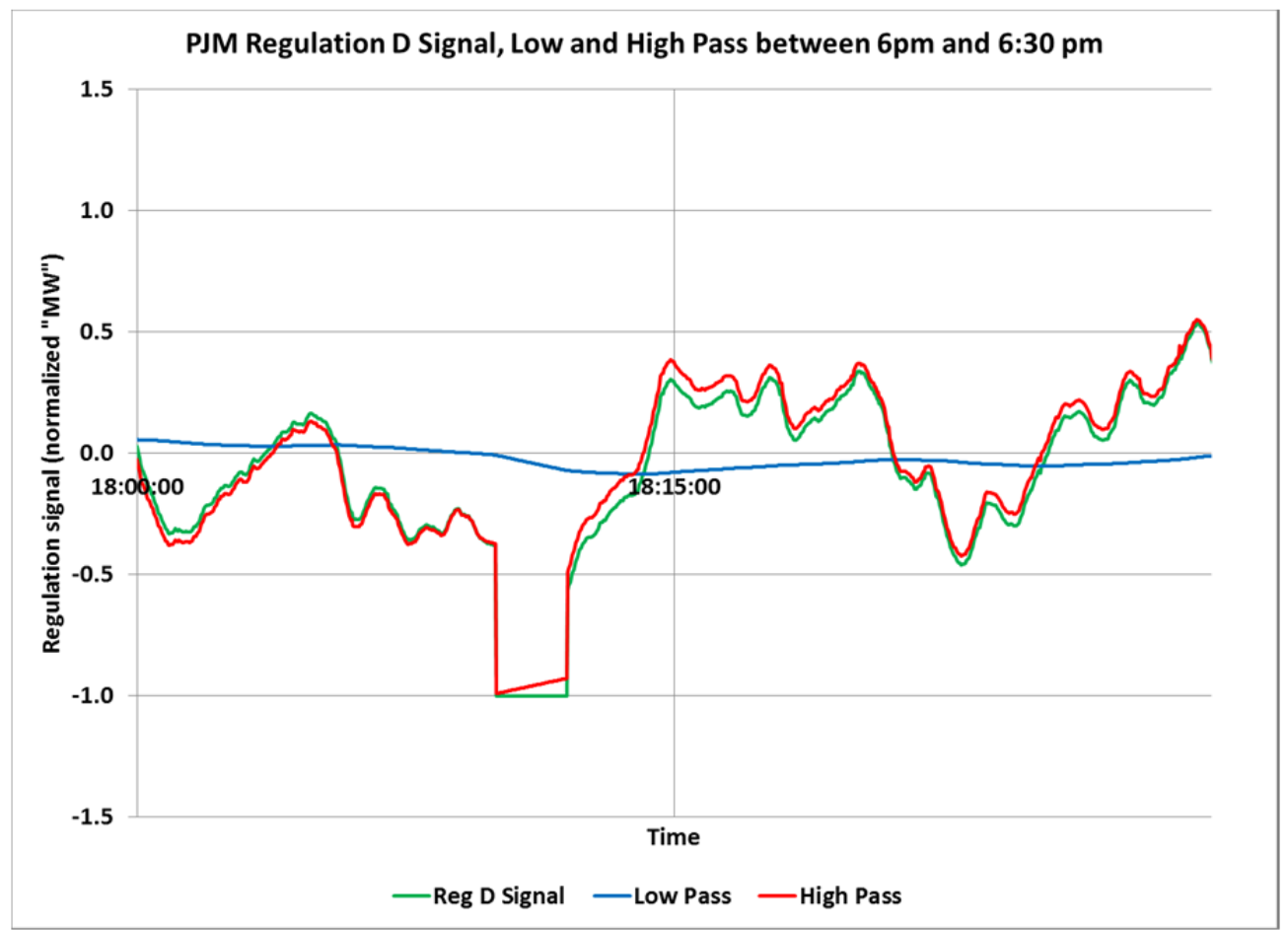

Figure 7.4. A Plot of the Signals Restricted to the Interval between 6 p.m. and 6:30 p.m. 


\subsubsection{Dispatch}

A very schematic approach to dispatch is outlined in this section. Regulation signal is sent at equal intervals every few seconds. The bid intervals are much longer, and the devices participating in regulation have to respond to the regulation signal. The signal should be scaled appropriately before it is applicable to the devices and it can change with each bid. This scaling can be done by the aggregator and the resulting regulation signal broadcast to the devices, or the scaling factor can be transmitted to the devices once at the beginning of the bid period, and the devices can receive regulation signal directly. Options for the communication mechanisms are briefly discussed in the next section.

Regulation presents a complex controls problem. Figure 2.3 shows considerable difference between the target regulation and actual. In Steffes (2011), an actual application of a water heater to provide regulation is given although not in the transactive context; the figure at the bottom right of Page 3 of this reference highlights the complexities of following the regulation signal.

To better understand control issues, let us consider a simple dispatch algorithm. First consider VSDs. Suppose that for one particular bid interval, the share of regulation for a particular VSD is $1 / 1000$ of the regulation signal. If the regulation signal is $3.5 \mathrm{MW}$, the VSD has to adjust by $3.5 \mathrm{~kW}$. How the VSD accomplishes this is a separate controls problem not addressed here. A good discussion of this as well as of VSDs providing regulation can be found in Hao et al. 2012. Water heaters must be controlled differently. Suppose regulation signals are received every 4 seconds. A portfolio of water heaters contains 1000 that are on and ready to be switched off for 4 seconds to provide their share of $10 \%$ of the regulation. Each device consumes different power, but let the total power for the 1000 units be 4 MW. A number equal to $10 \% /(4 \mathrm{MW})$ is communicated to the devices at the start of the bid interval, for e.g., 5 minutes and remains valid for the 5 minutes. When a regulation signal of $3.5 \mathrm{MW}$ is received, each of the 1000 devices turns off with a probability $(3.5 \mathrm{MW}) \times 10 \% /(4 \mathrm{MW})$ or $8.75 \%$. Each device is responsible to generate its own random number, and around 87 devices should be turned off. The standard error, if all units are identical, is $\sqrt{p(1-p) N}$ for a probability $p$. The number of devices is $N=1000$. In this example, the standard error is about 9 , so there can be substantial error in the regulation provided. If the regulation signal received 4 seconds later is $3.8 \mathrm{MW}$, the new probability is $9.5 \%$. However, some devices that were off in the previous interval may turn on, possibly resulting in inadequate regulation. If the regulation signal is negative, then the devices that are currently off are dispatched in a similar manner. The devices that were turned off in a previous interval may turn on in the next interval, possibly resulting in excess regulation.

The error in the regulation response can be reduced if the same devices that provided regulation up (thereby accumulating an energy debt) provide regulation down (by discharging the debt). This requires an analysis of its implications in the bid market. Another approach to dispatch is to deploy the resources in such a way that each resource need not respond every 4 seconds, but the ensemble provides a good quality regulation. In the context of a small number of large demand resources, such an approach has been developed in Aston (2012). Feasibility of such an approach for a large number of small demand resources will be addressed in the future. 


\subsection{Ramping and Spinning Reserve}

In the event the reserve is called, the resources whose bids cleared can be dispatched. How this dispatch is carried out and its impact on subsequent periods constitute significant control challenges. A stochastic approach to releasing HVAC devices at the end of an event is given in Zhang et al. (2012). When a large number of demand resources participate, and are released at the end of a spinning reserve event, it is possible, depending on how the recovery is staged, to introduce correlations between the on-times of the devices, resulting in low frequency oscillations that will likely damp out. If, as is not uncommon, there are successive 5-minute ramping events, it is important to understand the implications of releasing the devices that responded during the first 5 minutes. They can cause an imbalance in the system resulting in increased ramp requirement. One way, but not the only way, to avoid this is to continue to control the devices that responded in the first 5 minutes, possibly continuing to keep them in the off state. The market rules should be developed to allow such control. Another is for the aggregator to acquire energy resources to cover the recovery of these devices.

Consider an ensemble of identical devices for which a duty cycle can be defined: refrigerators or water heaters (but not clothes dryers), each using power $p$ when on. Suppose under normal operation, the duty cycle is such that a device is on for an interval $\Delta_{\text {on }}$ and off for an interval $\Delta_{\text {off. If }}$ the aggregator wants to acquire a portfolio of these devices from the bids such that a constant total power $P$ is consumed by these devices during the bid period, then it can be shown that s/he should acquire $N$ devices, where $N$ is given by

$$
\begin{gathered}
N=\frac{1}{D} \frac{P}{p} \\
D=\frac{\Delta_{o n}}{\Delta_{o n}+\Delta_{o f f}}
\end{gathered}
$$

If the aggregator has no knowledge of the status of the devices, a number $N$ of the devices can be chosen at random; on average, a fraction $D$ of these will be on at any time, with some distribution. The selection can be made more precise if the status of the device is included in the bid: from the ensemble of "on" devices, select

$$
N_{\text {on }}=\frac{P}{p}
$$

at random, and from the ensemble of "off" devices select

$$
N_{o f f}=\frac{1-D}{D} \frac{P}{p}
$$

at random.

Figure 7.5 shows various trajectories the system can take under normal operation and when some devices are forced to turn off. The system normally consumes a constant power and the path over a period of 5 minutes is given by $\mathrm{AB}$. If we follow the $N_{\text {on }}$ devices, some of them will go off over the 5 minutes and the power for these devices follows the path AC. Similarly, if we follow the $N_{\text {off }}$ devices, some of them will go on over the 5 minutes and the power for these devices follows the path DE. 
As a response to a contingency, if we turn off all $N_{\text {on }}$ at time 0 , and hold them in the off position for the 5 minutes, the system follows the path ADE. By staging how the $N_{o n}$ devices are turned off, we can arrive at any point between $\mathrm{C}$ and $\mathrm{G}$. We can even stage them in such a way that the regulation requirement in the interval is reduced.

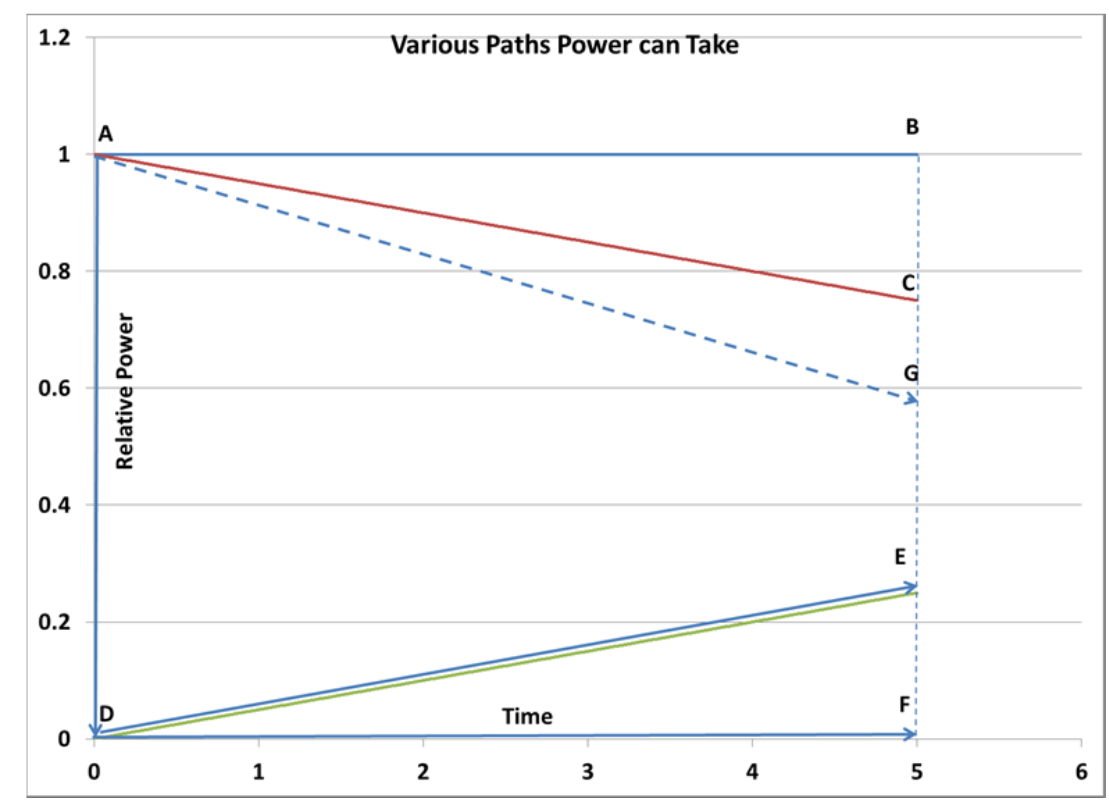

Figure 7.5. A Schematic Illustration of Paths an Ensemble of Devices can take during 5 minutes

Consider now a more realistic case of an ensemble of devices. Let $p(t)$ be the probability density function for a device to turn off at time $t$. Let us follow the devices that are on at time $t=0$. Let $N(t)$ be the expectation value of their number that are on at time $t$. For these devices that have remained on at time $t$, the probability density function to turn off at time $t^{\prime}(>t)$ is given by

$$
\frac{p(t \prime)}{\int_{t}^{\infty} d \tau p(\tau)}
$$

In the special case of $p(t)=\frac{1}{a} e^{-\frac{t}{a}}$ for some value $a$, then it is easy to see that we have a memoryless system popularly used in queueing theory: the probability that the device remains for the next $x$ minutes is independent of how long it has been on. Our formulation can accommodate general probability density functions. For example, the following function accommodates the case in which the longer a refrigerator is on, the more likely it is to turn off within the next interval.

$$
p(t)=\left\{\begin{array}{l}
\frac{1}{a} 0<t<a \\
0 \text { otherwise }
\end{array}\right.
$$

Define the cumulative probability

$$
P(t)=\int_{0}^{t} d \tau p(\tau)
$$


The probability that a device is on at time $t$ is given by $1-P(t)$. The number of devices that turn off between $t$ and $t+d t$ is given by

$$
d N(t)=-N(t) \frac{p(t) d t}{1-P(t)}
$$

If in addition, we have a forced attrition, i.e., $v(t) d t$ devices that are on are turned off between $t$ and $t+d t$, then the resulting differential equation is given by

$$
\frac{d N(t)}{d t}=-N(t) \frac{\dot{P}(t)}{1-P(t)}-v(t)
$$

where the dot denotes time derivative. This standard first-order differential equation can be solved to get the following solution:

$$
N(t)=(1-P(t)) N(0)-(1-P(t)) \int_{0}^{t} d \tau \frac{v(\tau)}{1-P(\tau)}
$$

This equation allows us to determine how to stage the forced attrition to get a desired profile, in particular to reduce the need for regulation. A stochastic algorithm based on Equation (7.10) for dispatch during a bid interval can be generated. As long as the bid interval ( $\sim 5$ minutes) is small compared to the mean duty cycle of the device, the equation remains valid. Also, evidently it is necessary that $N(t)>0$ for the equation to be valid.

The above results can be extended to a heterogeneous population of devices where each device has its own power $q_{i}$ and probability density function $p_{i}(t)$. We now have to consider the dynamics of each device separately. The above analysis can be repeated for the expectation value $\left\langle q_{i}(t)\right\rangle$ of the power at time $t$. It is convenient to define

$$
\rho_{i}(t) \equiv \frac{<q_{i}(t)>}{<q_{i}(0)>}
$$

The above analysis results in

$$
\rho_{i}(t)=\left(1-P_{i}(t)\right)\left(1-\int_{0}^{t} d \tau \frac{p_{i}^{f}(\tau)}{1-P(\tau)}\right)
$$

where $p_{i}^{f}(t) d t$ is the probability of forcibly turning off the device between times $t$ and $t+d t$. This gives us the profile of the expectation value of power for a given $p_{i}^{f}(t)$. It is of interest in control problems to determine $p_{i}^{f}(t)$ that results in a given $\rho_{i}(t)$ which determines profile of the expectation value of power. By inverting equation (7.12) we get

$$
p_{i}^{f}(t)=-\frac{\rho_{i}(t) p_{i}(t)}{\left(1-P_{i}(t)\right)}-\frac{d \rho_{i}(t)}{d t}
$$

The above formulation provides valuable insights into control and can form the basis for dispatch of an ensemble of heterogeneous devices to achieve a control objective. Further extensions are possible. As historical data on the performance of devices become available, control algorithms can be refined. A 
novel hierarchical distributed framework proposed in Kalsi et al 2013 can probably adapted for transactive controls. The framework involves two decision layers. The top decision layer determines the optimal gain for aggregated loads for each load bus. The gains are computed using decentralized robust control methods, and will be broadcast to the corresponding participating loads every control period. The second layer consists of a large number of heterogeneous devices, which switch probabilistically during contingencies so that aggregated power change matches the desired amount according to the most recently received gains. 


\subsection{Communication, Measurement, and Verification}

In order for the devices to send their bids, communication from the devices to the aggregator is necessary. The aggregator may be able to broadcast/multicast the price at which the bids cleared. Regulation signals, which are typically sent every few seconds and require response, need high speed communication. Internet as well as radio communication have been proposed as options. A synopsis of radio based communication can be found in NIST (2009).

To properly incentivize performance, it is necessary to verify that the devices provided the services that they contracted. From the ISO perspective, it is necessary to verify the performance of the aggregator. From the aggregator's perspective, it is necessary to verify the performance of the devices. Currently, the ancillary services are predominantly provided by the generators. Systems and rules to verify performance are geared toward generation assets consisting of a small number of large generators with sophisticated communication, control, and monitoring systems with dedicated staff. A large number of small demand resources must be handled in a very different manner. Even when demand resources participate, they provide a small part of ancillary services, and the resources are typically a few hundred large commercial and industrial loads. The $\mathrm{M} \& \mathrm{~V}$ methods used for these resources are not scalable when a very large number ( $\sim$ millions) of demand resources participate. Generally, the M\&V is done at the generators by the generation owner or at the commercial/industrial premises by the aggregator following the protocol and rules specified by the ISO. If this system is extended to a large number of demand resources, the aggregator would perform $M \& V$ of individual resources and thereby determine the performance of the ensemble.

Ideally, measurements should be performed at the device level. With significant advances in technology, this may be feasible. Even with current technology, just knowing the status (on or off) of the devices is valuable in $\mathrm{M} \& \mathrm{~V}$. Moving upstream from the device, smart meter readings are available at the premises level. When synchronized with the bids, device status and meter data can be used to estimate the device performance. While not essential, the meter data can be analyzed using nonintrusive load monitoring (NILM) systems. These can provide an estimate of individual consumption of various loads connected to the meter. In Gomatom et al. (2013), the authors give the results of testing various NILM systems. NILM is primarily intended for residential buildings, and works with energy use data recorded periodically, the typical period being 15 minutes. With additional hardware and imbedded software, it is possible to analyze the waveform to get more accurate estimates. It is possible that significant cost reductions can be achieved if a future generation of smart meters has the ability to measure and analyze waveforms. The M\&V analysis is valuable in refining the quantity bid by the resources. A database of the on-off status of the devices can help the aggregator in developing and validating population models, in addition to $\mathrm{M} \& \mathrm{~V}$. It is also valuable in estimating the uncertainties associated with resource acquisition and resource responses.

Future activities include:

- feasibility of web services for ancillary services including regulation

- evaluation of radio broadcast as an alternative to internet for some communication, especially regulation signals 
- coordination of industry trends in M\&V, e.g., (PJM 2011) into M\&V protocols

- evaluation of cost and benefits of nonintrusive load monitoring to supplement interval data. 


\subsection{Summary}

A transactive mechanism for a selected set of devices (refrigerators, water heaters, clothes dryers, and VSDs) to provide a selected set of ancillary services (spinning reserves, ramping reserves, and regulation) has been discussed. An analysis is presented that is necessary to develop specifications for simulations of a TC2 system with a range of

- characteristics of the devices

- characteristics of the services they are required to provide

- market designs

- control strategies.

The important results are summarized below:

- The regulation signal can be divided into an energy-neutral high frequency component and a low frequency component. The high frequency component is particularly well suited for demand resources. The low frequency component, which carries energy non-neutrality, can be handled by a combination of generators and demand resources. An explicit method for such a separation is obtained from an exponentially weighted moving average filter. Causal filters (i.e., filters that process only present and past values of a signal) introduce delays that can be issues in some signal processing applications that treat the high frequency part as a noise to be eliminated. For regulation, the high frequency component is an essential part of the signal. The delay in the low frequency component is not a problem.

A transactive bidding mechanism determines the set of devices chosen to provide the regulation service. The devices have to respond every few seconds (e.g., every 4 seconds) to the regulation signal. To keep the communication and computational burden manageable, the bidding interval is typically much longer (e.g., 5 minutes). A stochastic self-dispatch algorithm determines the response of the devices to the regulation signal.

The energy neutrality interval varies and can be quite different from the bid interval (e.g., 30 minutes versus 5 minutes). Devices that have just provided regulation up by reducing their energy use are in a better position to provide regulation down. Future simulation studies of the transactive mechanism for regulation are recommended.

- In an ensemble of devices under normal operation, some devices turn on and some turn off in any time interval. Demand response necessitates turning off devices that would normally be on, or turning on devices that would normally be off. Over time, some of these would have turned off on their own. A formalism to determine expectation values under a combination of natural and forced attrition has been developed. This formalism provides a mechanism for accomplishing a desired power profile within a bid period. In particular, a method to minimize regulation requirement can be developed. The formulation provides valuable insights into control. More realistic scenarios including multiple states of the devices can be analyzed using simulations. As historical data on the performance of devices become available, control algorithms can be refined. Methods developed for primary frequency control using a large number of heterogeneous devices may be relevant. 
A transactive bidding mechanism gives the set of devices chosen to provide the service. Analyses of the bidding and dispatch mechanisms for such a service through simulations are needed.

- If a contingency spans multiple bidding intervals, there is the possibility of gaming the system by bidding high in subsequent intervals. Analyses of methods for defending against such possibilities are needed.

- Some ancillary services - ramping to absorb unforecasted increase in renewable generation, and regulation down - require the demand resources to increase their energy use. Some resources such as HVAC systems can do this readily, whereas some others require enabling technology. Even without such technology, it is possible to arrange refrigerators and water heaters to have an energy debt and be ready to increase their energy use. A transactive bid mechanism of revolving debt can be developed for this purpose. Analyses of the bidding and dispatch mechanisms for such revolving energy debt through simulations are needed.

- At the end of a contingency call, the devices should be returned to their pre-contingency condition. This should be staged in a way that avoids a rebound in load resulting from too many devices turning on at once. A stochastic mechanism is one approach. Another is for the aggregator to plan for it in the energy market. A third is, in effect, a one-sided auction where the devices compete for an amount of energy that avoids such peaks. Analysis of measurement and verification of services using interval meter data, possibly augmented by non-intrusive load monitoring techniques are needed.

Identification of mechanisms available or likely to be available in the near future for communicating with a large number of devices, especially broadcasting regulation signals in a form appropriate for devices to respond are needed. These include internet and radio communications. 


\subsection{References}

Abdul-Rahman KH, H Alarian, M Rothleder, P Ristanovic, B Vesovic, and B Lu. 2012. "Enhanced System Reliability Using Flexible Ramp Constraint in CAISO Market." In Power and Energy Society General Meeting, 2013 IEEE, July 22-26, 2012, San Diego, California. Accessed October 1, 2013 at http://dx.doi.org/10.1109/PESGM.2012.6345371.

Amjady N and F Keynia. 2010. “A new spinning reserve requirement forecast method for deregulated electricity markets." Applied Energy 87(6):1870-1879.

Aston A. 2012. "In Focus: American Water - Energy-shifting at pumping station helps regulate the grid." A paid supplement to the Washington Post, Washington, D.C. Online. Available at http://www.enbala.com/contents/subs/IN_THE_NEWS/Articles/2012/2012-09-19-

Energy\%20Shifting\%20at\%20Pumping\%20Station\%20Helps\%20Regulate\%20the\%20Grid\%20\%20Corporate\%20Knights.pdf. Accessed October 1, 2013.

Battelle. 2013. "Our electricity system is changing." Pacific Northwest SMART GRID Demonstration Project, Richland, Washington. Accessed October 1, 2013 at http://www.pnwsmartgrid.org/transactive.asp.

Bloor K, A Howe, A Suardi, and S Frattesi. (2009) Dynamic Ancillary Service Provided By Loads With Inherent Energy Storage. RLtec, London, United Kingdom. Accessed October 1, 2013 at http://www.gridwiseac.org/pdfs/forum_papers09/howe.pdf.

CAISO (California Independent System Operator Corporation). 2011. Demand Response \& Proxy Demand Response - Frequently Asked Questions. Folsom, California. Accessed October 1, 2013 at http://www.caiso.com/271e/271ee8df2c760.pdf.

Cappers P, J MacDonald, and C Goldman. 2013. Market and Policy Barriers for Demand Response Providing Ancillary Services in U.S. Markets. LBNL-6155E, Ernest Orlando Lawrence Berkeley National Laboratory, Berkeley, California. Accessed October 1, 2013 at http://emp.lbl.gov/sites/all/files/lbnl-6155e.pdf.

Casey K. 2013. "California's Evolving Energy Market.” Harvard Electricity Policy Group - SeventyFirst Plenary Session, Calgary, Canada, June 13-14, 2013. Accessed October 1, 2013 at http://www.hks.harvard.edu/hepg/Papers/2013/Casey.pdf.

De Martini P. 2013. DR 2.0: A Future of Customer Response. Newport Consulting Group, Newport Beach, California. Accessed October 1, 2013 at http://www.demandresponsesmartgrid.org/Resources/Documents/FINAL_DR\%202.0_13.07.08.pdf.

DOE (U.S. Department of Energy). 2011. Load Participation in Ancillary Services. Workshop Report. Office of Energy Efficiency and Renewable Energy and Office of Electricity Delivery and Energy Reliability, Washington, D.C. Accessed October 1, 2013 at http://www1.eere.energy.gov/analysis/pdfs/load_participation_in_ancillary_services_workshop_report.pd f. 
EIA (U.S. Energy Information Administration). 2009. "RECS Public Use Microdata Files.” Online. Available at http://www.eia.gov/emeu/recs/recspubuse05/pubuse05.html. Accessed October 1, 2013.

EIA (U.S. Energy Information Administration). 2012. Online. "Most states have Renewable Portfolio Standards." Available at http://www.eia.gov/todayinenergy/detail.cfm?id=4850. Accessed October 4, 2013.

ELCAP (End Use Load and Consumer Assessment Program). 2013. "NW Council ELCAP Database." Online. Available at http://rtf.nwcouncil.org/ELCAP.htm. Accessed June 6, 2013.

Ellison JF, LS Tesfatsion, VW Loose, and RH Byrne. 2012. Project Report: A Survey of Operating Reserve Markets in U.S. ISO/RTO-managed Electric Energy Regions. SAND2012-1000, Sandia National Laboratories, Albuquerque, New Mexico. Accessed October 1, 2013 at http://www.sandia.gov/ess/publications/SAND2012_1000.pdf.

Endicott B. 2013. New Demand Response Revenue Streams: Intro to Economic DR \& Synchronized Reserve. Energy Smart 2013, EnerNOC, Boston, Massachusetts. Accessed October 1, 2013 at http://energysmart.enernoc.com/Portals/202241/docs/new_dr_revenue_streams.pdf.

ENERGY STAR. 2013. "Residential Refrigerators and Freezers Specification Version 5.0.” Online. Available at https://www.energystar.gov/products/specs/residential_refrigerators_and_freezers_specification_version_ 5_0_pd. Accessed June 15, 2013.

EPRI (Electric Power Research Institute). 2003. EPRI-DOE Handbook of Energy Storage for Transmission \& Distribution Applications. Final Report. Palo Alto, California. Accessed October 1, 2013 at http://www.sandia.gov/ess/publications/ESHB\%201001834\%20reduced\%20size.pdf.

FERC (Federal Energy Regulatory Commission). 2003. Wholesale Power Market Platform White Paper. April 28, 2003, Washington, D.C.

FERC (Federal Energy Regulatory Commission). 2011a. Order 755 FINAL RULE. Docket Nos. RM11-7-00 and AD10-11-000, Washington, D.C. Accessed October 1, 2013 at http://www.ferc.gov/whats-new/comm-meet/2011/102011/E-28.pdf.

FERC (Federal Energy Regulatory Commission). 2011b. FINAL RULE Order 745. Docket No. RM10-17-000, Washington, D.C. Accessed October 1, 2013 at http://www.ferc.gov/EventCalendar/Files/20110315105757-RM10-17-000.pdf.

FERC (Federal Energy Regulatory Commission). 2012. Energy Primer: A Handbook of Energy Market Basics. The Division of Energy Market Oversight, Office of Enforcement, Washington, D.C. Accessed on October 1, 2013 at http://www.ferc.gov/market-oversight/guide/energyprimer.pdf\#xml=http://search.atomz.com/search/pdfhelper.tk?sp_o=4,100000,0.

Fuller JC and GB Parker. 2012. Modeling of GE Appliances: Cost Benefit Study of Smart Appliances in Wholesale Energy, Frequency Regulation, and Spinning Reserve Markets. PNNL-22128, Pacific Northwest National Laboratory, Richland, Washington. 
Fuller JC, B Vyakaranam, SM Leistritz, and GB Parker. 2013. Modeling of GE Appliance: Final Presentation. PNNL-22204, Pacific Northwest National Laboratory, Richland Washington.

Gomatom K, C Holmes, and D Kresta. 2013. “Non-Intrusive Load Monitoring.” Presented at Emerging Technologies Showcase, August 14, 2013. Online. Available at

http://e3tnw.org/Documents/NILMs\%20Showcase\%20Aug2013.pdf. Accessed October 1, 2013.

Hammerstrom DJ, R Ambrosio, TA Carlon, JG DeSteese, GR Horst, R Kajifasz, LL Kiesling, P Michie, RG Pratt, M Yao, J Brous, DP Chassin, RT Guttromson, OM Jarvegren, S Katipamula, NT Le, TV Oliver, and SE Thompson. 2008. Pacific Northwest GridWise ${ }^{\mathrm{TM}}$ Testbed Demonstration Projects: Part I. Olympic Peninsula Project. PNNL-17167, Pacific Northwest National Laboratories, Richland, Washington.

Hao H, T Middelkoop, P Barooah, and S Meyn. 2012. "How demand response from commercial buildings will provide the regulation needs of the grid." In Fiftieth Annual Allerton Conference on Communication, Control and Computing, October 1-5, 2012, Monticello, Illinois. Accessed October 1, 2013 at http://ieeexplore.ieee.org/xpl/articleDetails.jsp?arnumber=6483455.

Hendron R and C Engebrecht. 2010. Building America House Simulation Protocols. National Renewable Energy Laboratory, Washington, D.C.

K Kalsi, W. Zhang, J Lian, LD Marinovici, C Moya, JE Dagle. 2013. "Distributed Smart Grid Asset Control Strategies for Providing Ancillary Services” PNNL-22875.

Kirby BJ. 2006. Demand Response For Power System Reliability: FAQ. ORNL/TM-2006/565, Oak Ridge National Laboratory, Oak Ridge, Tennessee. Accessed October 1, 2013 at http://web.ornl.gov/sci/ees/etsd/pes/pubs/TM_2006_565_Demand_Response_For_Power_System_Reliab ility_FAQ.pdf.

MacDonald J, P Cappers, D Callaway, and S Kiliccote. 2012. Demand Response Providing Ancillary Services, A Comparison of Opportunities and Challenges in the US Wholesale Markets. LBNL-5958E, Ernest Orlando Lawrence Berkeley National Laboratory, Berkeley, California. Accessed October 1, 2013 at http://drrc.lbl.gov/sites/drrc.lbl.gov/files/LBNL-5958E.pdf.

Marceau M and R Zmeureanu. 1999. "Nonintrusive load disaggregation computer program to estimate the energy consumption of major end uses in residential buildings." Energy Conversion \& Management 41(13):1389-1403.

Margossian B. 1994. "Deriving End-Use Load Profiles Without End-Use Metering: Results of Recent Validation Studies." In ACEEE Summer Study on Energy Efficiency in Buildings, Vol 2, Demand and load shapes. American Council for an Energy-Efficient Economy, Washington, D.C. Online. Available at http://cgec.ucdavis.edu/ACEEE/1994-96/1994/VOL02/217.PDF. Accessed June 6, 2013.

NERC (North American Electric Reliability Corporation). 2011. Balancing and Frequency Control. A Technical Document. NERC Resources Subcommittee, Princeton, New Jersey. Accessed October 1, 2013 at

http://www.nerc.com/docs/oc/rs/NERC\%20Balancing\%20and\%20Frequency\%20Control\%20040520111. pdf. 
NIST (National Institute of Standards and Technology). 2009. Available at http://collaborate.nist.gov/twiki-sggrid/pub/SmartGrid/H2G/Bcast09d.pdf.

Olsen DJ, N Matson, MD Sohn, C Rose, J Dudley, S Goli, S Kiliccote, M Hummon, D Palchak, J Jorgenson, and P Denholm. 2013. Grid Integration of Aggregated Demand Response, Part 1: Load Availability Profiles and Constraints for Western Interconnection. Lawrence Berkeley National Laboratory and National Renewable Energy Laboratory, Berkeley, California, and Golden, Colorado.

Perlstein B, E Gilbert, F Stern, K Corfee, L Battenberg, R Maslowski, S Schare, and R Firestone. 2012. Potential Role of Demand Response Resources in Maintaining Grid Stability and Integrating Variable Renewable Energy under California's 33 Percent Renewable Portfolio Standard. Prepared for California's Demand Response Measurement \& Evaluation Committee (DRMEC) by Navigant Consulting, Inc., San Francisco, California. Accessed October 1, 2013 at http://www.calmac.org/publications/7-18-

12_Final_White_Paper_on_Use_of_DR_for_Renewable_Energy_Integration.pdf.

PJM. 2011. RPSTF Performance Metrics - Implementation using Formulas and Examples. Online. Available at http://www.pjm.com/ /media/committees-groups/task-forces/rpstf/20110823/20110823rpstf-performance-metrics-proposal-presentation.ashx. Accessed October 1, 2013.

Powers J, B Margossian, and BA Smith. 1991. "Using a rule-based algorithm to disaggregate end-use load profiles from premise-level data." In IEEE Computer Applications in Power, vol. 4, issue 2, pp. $42-47$.

Pratt R and D Najewicz. 2011. Opportunities for Mass Market Demand Response to Provide Ancillary Services. Presented at DOE/OE/EERE Workshop, October 2011, Washington, D.C. Accessed October 1, 2013 at

http://www1.eere.energy.gov/analysis/pdfs/opportunities_for_mass_market_dr_for_as_rob_pratt_pnnl_an d_dave_najewicz_ge.pdf.

Pratt RG, CC Conner, EE Richman, KG Ritland, WF Sandusky, and ME Taylor. 1989. Description of Electric Energy Use in Single Family Residences in the Pacific Northwest. DOE/BP 13795 21, Bonneville Power Administration, Portland, Oregon.

Rudermann H, JH Eto, K Heinemeier, A Golan, and DJ Wood. 1989. Residential End-Use Load Shape Data Analysis. UER-216, Lawrence Berkeley Laboratory, Berkeley, California.

Shogren E. 2013. "The Grid Of The Future Could Be Brought To You By ... You.” National Public Radio, August 14, 2013. Accessed October 1, 2013 at http://www.npr.org/2013/08/14/212020224/thegrid-of-the-future-could-be-brought-to-you-by-you.

Steffes P. 2011. Grid-Interactive Electric Thermal Storage (GETS) Water Heating - "Smart" domestic Space and Water Heaters provide affordable energy storage and grid control for ancillary value, renewable integration and other grid optimization. SC12012 - Rev 4, Steffes Corporation, Dickinson, North Dakota. Accessed October 1, 2013 at http://www.steffes.com/LiteratureRetrieve.aspx?ID=115580. 
TESA (Texas Energy Storage Alliance). 2010. Storage Participation in ERCOT. Texas. Accessed October 1, 2013 at

http://www.ercot.com/content/gridinfo/etts/keydocs/ERCOT_Storage_Issues_Whitepaper.doc

Widergren S, C Marinovici, T Berliner, and A Graves. 2012. "Real-time pricing demand response in operations." In Power and Energy Society General Meeting, 2012 IEEE, pp. 1,5, July 22-26, 2012, San Diego, California.

Zhang W, K Kalsi, J Fuller, M Elizondo, and D Chassin. 2012. “Aggregate Model for Heterogeneous Thermostatically Controlled Loads with Demand Response." In Power and Energy Society General Meeting, 2012 IEEE, pp. 1,8, July 22-26, 2012, San Diego, California. 


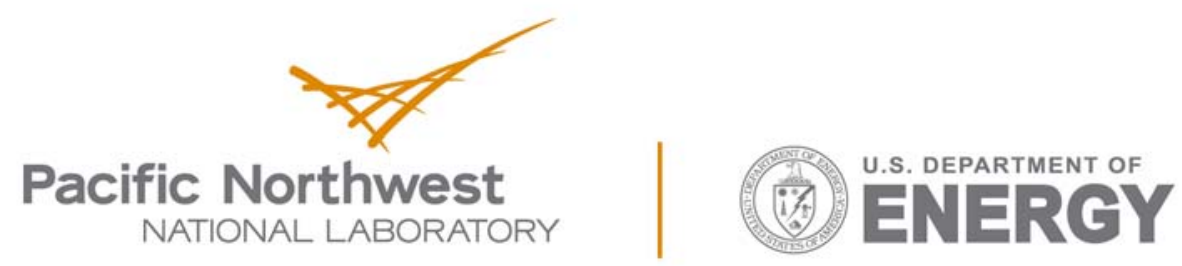

Proudly Operated by Battelle Since 1965

902 Battelle Boulevard

P.O. Box 999

Richland, WA 99352

1-888-375-PNNL (7665)

www.pnnl.gov 